Published in final edited form as:

Nat Rev Drug Discov. 2017 December 28; 17(1): 78. doi:10.1038/nrd.2017.267.

\title{
JAK inhibition as a therapeutic strategy for immune and inflammatory diseases
}

\author{
Daniella M. Schwartz ${ }^{1}$, Yuka Kanno ${ }^{1}$, Alejandro Villarino ${ }^{1}$, Michael Ward ${ }^{2}$, Massimo \\ Gadina $^{3}$, and John J. O'Shea ${ }^{1}$ \\ ${ }^{1}$ Molecular Immunology and Inflammation Branch, National Institute of Arthritis and \\ Musculoskeletal and Skin Diseases, National Institutes of Health \\ ${ }^{2}$ Clinical Trials and Outcomes Branch, National Institute of Arthritis and Musculoskeletal and Skin \\ Diseases, National Institutes of Health \\ ${ }^{3}$ Translational Immunology Section, National Institute of Arthritis and Musculoskeletal and Skin \\ Diseases, National Institutes of Health
}

\begin{abstract}
Proof provided by biological therapies that cytokines are truly key drivers of immune-mediated diseases has spurred effort in targeting their associated signaling pathways. Small-molecule drugs that inhibit Janus kinases (jakinibs), which are essential signaling mediators downstream of many pro-inflammatory cytokines, have gained traction as safe and efficacious options for the treatment of inflammation-driven pathologies like rheumatoid arthritis, psoriasis and inflammatory bowel disease. Building on the clinical success of first-generation jakinibs, second-generation compounds which claim greater selectivity are currently undergoing development and proceeding to clinical trials. However, important questions remain about the advantages and limitations of improved JAK selectivity, optimal routes and dosing regimens, and how best to identify patients that will benefit from jakinibs. This review will discuss the biology of jakinibs from a translational perspective, focusing on recent insights from clinical trials, the development of novel agents, and the use of jakinibs in a spectrum of immune and inflammatory diseases.
\end{abstract}

\section{Introduction}

The discovery of the numerous cytokines underlying the pathogenesis of allergic, inflammatory and autoimmune disorders has provided a basis for the development of highly successful therapeutic monoclonal antibodies and recombinant proteins that target several such cytokines and their receptors ${ }^{1}$. Such therapies have dramatically altered outcomes for a range of diseases, including rheumatoid arthritis (RA), psoriasis and Inflammatory Bowel Disease (IBD) ${ }^{1}$. However, even for a disorder like rheumatoid arthritis (RA) in which much progress has been made, most patients do not respond completely to currently available therapies, and there are relatively few examples of long-term remissions after cessation of therapy ${ }^{2}$. For other disorders, there has been even less progress, especially diseases in which fibrosis and tissue destruction are major features, such as systemic sclerosis.

Thus, despite substantial advances, there is still a major need for novel therapeutic strategies for immune and inflammatory diseases. If targeting specific cytokines outside the cell is 
inadequate, an obvious alternative strategy is to target the action of multiple cytokines inside the cell. However, given the complex molecular basis of cytokine action, this can be a daunting task. In this review, we will discuss one class of drugs, Janus kinase (JAK) inhibitors (jakinibs), briefly discussing the role of JAKs in cytokine signaling, the rationale for targeting these kinases, the status of current jakinibs, and future directions in this field including their potential utility in a wide variety of immune-mediated diseases.

\section{The rationale for targeting JAKs}

The term "cytokine" encompasses many structurally unrelated proteins that are grouped based on their binding to distinct receptor superfamilies. These cytokine receptor superfamilies include: the tumour necrosis factor (TNF) receptor family, the interleukin (IL)-1 receptor superfamily, the IL-17 receptor superfamily, the transforming growth factor (TGF) receptor superfamily, the receptor tyrosine kinase superfamily and the seventransmembrane receptor superfamily. These cytokines have critical roles in the pathogenesis of immune-related diseases, but do not depend upon JAKs for signal transduction. Although drugs that target several such cytokines (e.g. "biologics"), particularly TNF, are widely used in the treatment of immune-mediated disorders such as rheumatoid arthritis, psoriasis and inflammatory bowel disease, these have been well-described elsewhere ${ }^{3-6}$.

This review instead focuses on the signalling pathways for Type I and Type II cytokine receptors, a family of receptors employed by over 50 cytokines, interleukins, interferons, colony stimulating factors, and hormones. Like other receptor superfamilies, Type I and Type II cytokine receptors are related by their mode of intracellular signaling: they all employ JAKs (Figure 1), a small family of kinases - JAK1, JAK2, JAK3 and Tyrosine Kinase 2 (TYK2) - that bind directly to the intracellular domains of Type I/II cytokine receptors and not to other classes of cytokine receptors (Figure 2).

There are several reasons why targeting JAKs might be a reasonable therapeutic strategy for immune-mediated diseases. An overwhelming body of evidence has established that JAKdependent cytokines are major contributors to immunopathology and that blocking such cytokines with biologics can be beneficial in immune-mediated diseases. For instance, IL-6 is a prototypic proinflammatory cytokine commonly overexpressed in many autoimmune and inflammatory diseases ${ }^{7}$, and is a driver of acute phase responses including induction of C-reactive protein (CRP) and Serum Amyloid A ${ }^{8}$. The efficacy of monoclonal antibodies that target IL-6 or its receptor in rheumatological diseases confirms the criticality of this cytokine in immunopathogenesis ${ }^{7}$. Similarly, there is extensive data to support the pathogenic role of IL-12 and IL-23 in inflammatory bowel disease (IBD) and psoriasis; the efficacy of ustekinumab, a monoclonal antibody targeting the p40 subunit of both cytokines, strongly supports this conclusion ${ }^{9}$. The overexpression of IL-4, IL-5, and IL-13 in allergic disease and the success of drugs that target these cytokines ${ }^{10-12}$ provide yet another compelling argument for the potential utility of interfering with Type I/II cytokine signaling in disorders such as asthma and atopic dermatitis. Many other JAK-dependent cytokines have been shown in various settings to contribute to inflammatory diseases. These include but are not limited to: interferons, IL-15, IL-21, granulocyte colony stimulating factor (G$\mathrm{CSF})$, and granulocyte-macrophage (GM)-CSF${ }^{1}$. 
It is well-established that Type I/II cytokine receptors require JAKs to exert their effects, and that other receptor superfamilies do not. The dependence of Type I and Type II cytokines on JAKs was established in a variety of genetic models from mutagenized cell lines and knockout mice to humans with mutations - these approaches all confirmed that JAKs are essential for signaling by cytokines that use Type I and Type II receptors $1,13,14$.

Polymorphisms in JAK and STAT genes are associated with autoimmunity, and loss-offunction mutations cause immunodeficiency due to the inability of Type I/II cytokines to transmit signals through their receptors $1,13,14$. More recent phosphoproteomic analysis established that for the IL-2 receptor, at least $90 \%$ of signaling is JAK dependent ${ }^{15}$. The criticality of this straightforward pathway to Type I/II cytokine signaling was compelling evidence that interfering with the activity of JAKs could lead to a new class of immunomodulatory drugs ${ }^{16,17}$, and also indicated some potential adverse effects of JAK blockade.

\section{Can JAKs be successfully, specifically, and safely targeted?}

JAKs are tyrosine kinases, meaning that they transfer phosphate from ATP to tyrosine residues on other proteins, including cytokine receptors, JAKs themselves and downstream signaling molecules. Tyrosine phosphorylation of kinases, including JAKs, triggers their enzymatic activity. Additionally, tyrosine phosphorylation of receptors causes the recruitment of signaling molecules that bind to the phosphorylated tyrosines of the ligandengaged receptor. One critical class of signaling molecules for Type I/II cytokine receptors is the STAT (signal transducer and activator of transcription) family of DNA binding proteins (Figure 1). Phosphorylated STATs translocate to the nucleus, bind DNA, and drive gene transcription. This simple pathway is essential for the effects of cytokines that bind Type I/II receptors, but it is not used by TNF, IL-1, IL-17 or other cytokines.

In the early 2000s, the success of the tyrosine kinase inhibitor imatinib for the treatment of chronic myelogenous leukemia provided startling evidence that targeting kinases was not only feasible, but could be game-changing ${ }^{18}$. The oncology field moved ahead quickly and now 31 kinase inhibitors have been approved by the FDA for the treatment of various cancers ${ }^{19,20}$. Not surprisingly, the first jakinib to gain FDA approval was designed for neoplastic rather than immune-mediated diseases. A V617F mutation in $J A K 2$ is strongly associated with myeloproliferative neoplasms, including myelofibrosis (MF), polycythemia vera (PV), and essential thrombocythemia (ET), occurring in nearly $100 \%$ of PV patients and over $75 \%$ of ET patients ${ }^{21}$. The JAK pseudokinase domain attenuates kinase activity, and mutations in this domain can result in constitutive activation of JAK2, which signals downstream of erythropoietin (EPO), granulocyte-macrophage colony stimulating factor (GM-CSF), and thrombopoietin (TPO). V617F is an acquired mutation, so proliferation is restricted to the lineage expressing the mutant allele. These observations were a strong rationale for the development of the JAK1/JAK2 inhibitor ruxolitinib (Figure 3), and the clinical trials that led to its approval by the FDA in 2011 showed that JAK inhibition was not only possible, but safe and effective for these indications ${ }^{22,23}$. Indeed, the JAK-STAT pathway is constitutively activated in many cancers ${ }^{1324}$, which has led to the initiation of multiple trials using jakinibs in hematological and solid tumours, including trials in which multiple kinase inhibitors are used in combination (e.g. NCT02912754). 
While targeting kinases may be sufficiently safe and effective in the setting of neoplastic disorders, it is a very different question as to whether such drugs can be used long term in patients with immune-mediated disease, particularly given the greater need for a 'clean' safety profile outside of life-threatening diseases such as cancer. A large body of evidence leading to the acceptance of jakinibs as a therapy for RA has started to answer this question and will now be reviewed briefly.

\section{Rheumatoid arthritis}

Tofacitinib (Figure 3), a first-generation jakinib that inhibits JAK3, JAK1, and to a lesser degree JAK2, is the first jakinib developed for the treatment of autoimmune disease. It has been studied in a variety of preclinical models from transplant rejection to arthritis ${ }^{25-27}$. More importantly, multiple clinical trials including six Phase 3 trials studying tofacitinib in RA have been completed, encompassing more than 6000 subjects followed for as long as 8 years ${ }^{28-32}$. These trials have shown that tofacitinib is efficacious for new and established disease $^{33}$, as monotherapy ${ }^{34}$ or in combination with methotrexate (MTX) ${ }^{32}$, and in treatment-naive ${ }^{31}$ or treatment refractory patients ${ }^{29,30}$. Patients achieved significant amelioration of disease activity, as measured by the American College of Rheumatology $20 \%, 50 \%$, and $70 \%$ (ACR20, 50,70) response criteria. Patients also reported improvements in functional status measured by the HAQ-DI (health assessment questionnaire - disability index) and SF-36 (short form 36). Tofacitinib was proven superior to methotrexate $28,31,35$, noninferior to adalimumab ${ }^{30}$, and effective in patients who had failed multiple biologics $^{36,37}$. Moreover, tofacitinib was shown to prevent the progression of structural joint disease using conventional radiography and magnetic resonance imaging $28,35,38$. The largest radiographic treatment effect was seen in patients with the most baseline structural damage, but improvement was also noted in other groups ${ }^{39}$. Based on these and other findings, tofacitinib $5 \mathrm{mg}$ twice daily was approved by the Food and Drug Administration (FDA) for the treatment of rheumatoid arthritis in 2012 for patients intolerant of or unresponsive to MTX ${ }^{40}$. Since then, its effectiveness has been borne out in long-term extension studies tracking disease activity in $>4000$ patients ${ }^{2,4142-44}$. This is particularly true for disease activity measures that incorporate the CRP ${ }^{45}$, which may reflect blockade of IL- 6 signaling 8,46 . Tofacitinib has also been effective in improving patient-reported outcomes ${ }^{36,4748}$ and other disease measures that do not incorporate CRP ${ }^{45}$. After reviewing long-term safety and efficacy data, the European Medical Agency (EMA) also recommended approving tofacitinib for RA in January 2017. In addition, an extended release version of that uses osmotic delivery to allow once daily dosing was recently FDA-approved for the treatment of $\mathrm{RA}^{49}$.

Baricitinib is a first-generation jakinib with activity against JAK1 and JAK2 (Figure 3) that is structurally related to ruxolitinib. Baricitinib is cleared by the kidney, and is not metabolized via the cytochrome P450 (CYP) system, which sets it apart from tofacitinib and ruxolitinib ${ }^{50}$. It has been studied extensively in the treatment of RA, with extensive phase 3 trial data demonstrating safety and efficacy. Patients with RA refractory to conventional DMARDs (cDMARDs) displayed clinically significant improvements in disease activity, in radiographically assessed structural damage, and in patient-reported outcomes ${ }^{51}$. Baricitinib was also effective in patients who failed standard-of-care treatment with TNF inhibitors and 
in treatment-naive patients, where it outperformed methotrexate ${ }^{52,53}$. Baricitinib was superior to the TNF inhibitor adalimumab in methotrexate-refractory patients, a previously unseen milestone ${ }^{54}$. Baricitinib has been approved by the European Medicines Agency (EMA) for the treatment of RA. The FDA issued a Complete Response Letter, indicating that it was unable to approve the application for baracitinib, citing the need for additional clinical data to determine the most appropriate doses and clarify safety concerns 55 .

Peficitinib blocks all four JAK isoforms but has slight JAK3 selectivity (Figure 3) ${ }^{56}$. RA patients treated with peficitinib as monotherapy or in combination with MTX achieved clinical responses similar to those seen with other jakinibs ${ }^{5657}$.

\section{Other forms of arthritis}

TNF inhibitors have been effective in the treatment of other forms of arthritis, but like RA, are often not completely effective, and our understanding of the role of various cytokines in other arthritides is very incomplete. Nonetheless, tofacitinib was shown to be effective in psoriatic arthritis ${ }^{58}$, where it reduces inflammatory cytokine production by synoviocytes 59 . There was a trend toward higher response rates with tofacitinib than with the standard-ofcare TNF inhibitor adalimumab, but the trial was not adequately powered to assess superiority. If this finding is replicated in larger studies, it would be an exciting advance in the treatment of psoriatic joint disease. Tofacitinib also demonstrated efficacy in ankylosing spondylitis, another seronegative spondyloarthropathy, although results were difficult to interpret due to a high placebo response rate 60,61 . The efficacy of tofacitinib in seronegative spondyloarthropathy represents a potentially important advance, since the therapeutic armamentarium for this group of diseases comprises only three FDA-approved classes of drugs: TNF inhibitors, the IL12/23 blocking agent ustekinumab, and the IL-17 blocking agent secukinumab. Tofacitinib is also being evaluated in the treatment of juvenile idiopathic arthritis (JIA) (NCT01500551, NCT02592434), as it was reported effective in an adult patient with longstanding treatment-refractory polyarticular disease 62 .

\section{IBD}

IBD is a term that encompasses two diseases, ulcerative colitis (UC) and Crohn's disease (CD), but more likely represents a broad constellation of inflammatory disorders of the gastrointestinal tract driven by multiple diverse mechanisms that affect tissues beyond the gut, including joints. UC is typically restricted to the colon and primarily affects the mucosa, whereas CD is characterized by transmural inflammation, skip lesions, and inflammation throughout the gastrointestinal tract; however, there can be considerable overlap between the two diseases. Despite the success of biologics including TNF blockers, ustekinumab, and vedolizumab (an $a_{4} \beta_{7}$ integrin inhibitor), current IBD therapies are ineffective for many patients. Tofacitinib $10 \mathrm{mg}$ twice daily has proven an effective induction treatment for both moderate and severe UC, inducing remission and mucosal healing in a significant proportion of patients ${ }^{63}$. A subsequent UC trial has demonstrated that both $5 \mathrm{mg}$ and $10 \mathrm{mg}$ doses of tofacitinib are effective in maintaining remission for up to 1 year ${ }^{63}$. Results in CD have been less consistent ${ }^{64}$, with the most recent data suggesting a very modest treatment effect for both induction and maintenance therapy ${ }^{65}$. The basis for differences in efficacy is unknown, 
but it could relate to the basic mechanism of disease and differential contribution of various JAK-dependent cytokines to immunopathogenesis. JAK-dependent cytokines like IL-6 are generally implicated in IBD pathogenesis; however, IL-9 is thought to be involved the pathogenesis of UC but not in that of $\mathrm{CD}^{66}$. Moreover, the JAK-dependent cytokine IL-10 has critical anti-inflammatory effects in the gut, therefore blockade with jakinibs has the potential for being detrimental. Impaired barrier function with dysbiosis and bacterial overgrowth are integral to the pathogenesis of IBD. The type I/II cytokines IL-22 and IL-9 are important for maintaining barrier integrity 67,68 , underlying another potential mechanism by which jakinibs could be detrimental in IBD. IL-17, also important for gut barrier function, does not signal via JAKs but is regulated by IL-6 and IL-23, which are JAKdependent. In the case of IL-17, clinical trials using IL-17A blocking antibodies to treat IBD showed unexpected disease exacerbations, possibly due to loss of mucosal protection ${ }^{69},{ }^{70}$. It is also possible that immunodeficiency underlies some forms of IBD and thus disease could be exacerbated by jakinibs. ${ }^{71}$ Further data from late-phase clinical trials, and a more sophisticated understanding of disease pathogenesis should help to clarify these concerns and identify the best candidates for treatment with jakinibs.

\section{Psoriasis}

Psoriasis is an autoimmune skin disorder, which is responsive to targeting multiple cytokines including TNF, IL-17, IL-12/23 and IL-23 alone. Given the JAK-dependence of multiple cytokines involved in psoriasis pathogenesis, tofacitinib has been tested extensively in latephase clinical trials for the treatment of this disease. Patients treated with tofacitinib experienced clinically significant improvements in the PASI 50/75/90 (Psoriasis Activity and Severity Index 50\%/75\%/90\% improvement) at both $5 \mathrm{mg}$ and $10 \mathrm{mg}$ twice daily doses ${ }^{72,73}$. Tofacitinib rapidly blocked STAT phosphorylation in keratinocytes from psoriasis patients and abrogated keratinocyte-induced pathogenic cytokine signaling - both of which may underlie its efficacy ${ }^{74}$. However, in a trial directly comparing tofacitinib to standard-of-care treatment with etanercept (a TNF inhibitor) only the $10 \mathrm{mg}$ twice daily (BID) dose of tofacitinib showed noninferiority ${ }^{75}$. The FDA issued a Complete Response Letter indicating that it would not be able to approve tofacitinib for psoriasis without additional information

76. Likely this relates to the need to establish that the $10 \mathrm{mg}$ BID dose provides an appropriate safety/benefit ratio, which was the reason why only the $5 \mathrm{mg}$ dose was approved for RA.

Baricitinib was also found to be efficacious in a phase 2 study testing its effect in patients with moderate-to-severe psoriasis with over $50 \%$ of patients achieving a sustained response as measured by the PASI $75^{77}$. These responses were also seen predominantly at the higher, 8 $\mathrm{mg}$ and $10 \mathrm{mg}$, daily doses and baricitinib has not been compared with TNF inhibitors.

Additional safety data that has emerged over the last 2 years may influence future decisions regarding FDA or EMA approval, as may the adoption of IL-17 blocking agents secukinumab and ixekizumab as a new and more effective standard-of-care in psoriatic skin disease.

Peficitinib also appeared effective for psoriasis in a Phase 2 trial $^{78}$, although no Phase 3 trials are currently recruiting patients. 
Considering the risks associated with systemic JAK inhibition, topical formulations are an attractive alternative for cutaneous disease. Topical formulations of tofacitinib and ruxolitinib have been developed and tested in Phase II studies in psoriasis. Treatment with topical tofacitinib demonstrated significantly higher response rate at 8 weeks compared with placebo, but the efficacy was transient ${ }^{79}$. Trials with topical ruxolitinib demonstrated improvement in psoriasis compared to treatment with placebo or other topical approved therapies, but as with tofacitinib, it was not a sustained improvement after discontinuation. 80,81 . Importantly, systemic absorption was minimal and there was no evidence of systemic toxicity ${ }^{81}$.

\section{Alopecia areata}

Alopecia areata (AA) is an autoimmune disorder in which hair follicles overexpress a variety of proinflammatory cytokines. Several case reports have been published using jakinibs to treat AA, alopecia totalis (affecting the entire scalp), and alopecia universalis, (affecting the entire body). Moreover, AA is characterized by tissue upregulation of genes induced by IFN- $\gamma$, which signals through JAK1 and JAK2 ${ }^{1,82}$. Early phase clinical trials and large retrospective studies indicate that tofacitinib ${ }^{83-86}$ ruxolitinib and baricitinib ${ }^{87,88}$ are effective for the spectrum of autoimmune forms of alopecia. However, symptoms recur upon drug discontinuation ${ }^{89}$, and tofacitinib may lose efficacy in some patients ${ }^{90}$. Topical ruxolitinib has also demonstrated efficacy in treatment of alopecia areata ${ }^{91}$ and there is an ongoing clinical trial evaluating the efficacy of topical tofacitinib (NCT02812342). Of considerable interest, it also appears that JAK inhibition can promotes hair regrowth; this is an area that clear will attract more investigation ${ }^{84}$.

\section{Atopic dermatitis}

Atopic dermatitis or atopic eczema is a common disorder in which cytokines associated with allergic disease frequently dominate (e.g. IL-4, IL-5 and IL-13). The pathogenic role of cytokines is evidenced by the utility of biologics targeting these cytokines. Oclacitinib (Figure 3) is the first jakinib to be FDA-approved for allergic and atopic canine dermatitis 92,93 . However, this provides a strong precedent for the use of jakinibs to treat atopic dermatitis in humans, and preclinical studies indicate that this would likely be an effective strategy 94,95 . Inflammation in atopic dermatitis is often complicated by concomitant irritant contact disease, a disease in which JAK-dependent cytokines like IL-6 and IL-31 play an important role ${ }^{96}$, and in which JAK2 inhibitors appear to reduce pathology ${ }^{97}$. A clinical trial using baricitinib to treat atopic dermatitis is ongoing (NCT02576938). Balancing efficacy and safety is always a priority, especially in this disease where morbidity may be high but mortality is low, so topical formulations of jakinibs are desirable if efficacious ${ }^{98}$. Tofacitinib ointment is efficacious in the treatment of atopic dermatitis, with an $80 \%$ improvement in EASI Eczema Area and Severity Index (EASI) score after 4 weeks of treatment ${ }^{99}$. One prominent feature of $\mathrm{AD}$ is pruritus, which results in an itch-scratch cycle. Cytokines have also been linked to the molecular pathogenesis of pruritus, such that treating with jakinibs might break the scratch-itch cycle ${ }^{100}$. 


\section{Other dermatologic conditions}

Tofacitinib has been reported efficacious in the treatment of vitiligo ${ }^{101}$, and a clinical trial using topical ruxolitinib for this indication is ongoing (NCT02809976). Palmoplantar pustulosis ${ }^{102}$, a refractory form of psoriatic skin disease that can be associated with arthritis, has also been treated successfully with tofacitinib. Finally, a case of the mucocutaneous disease idiopathic erythema multiforme (EM) associated with mutation of the TRPS1 gene and JAK-STAT activation was treated successfully with tofacitinib ${ }^{103}$. It would be intriguing to see whether other dermatologic diseases might be similarly responsive to jakinibs: candidates would include mycosis fungoides, graft-versus-host-disease (GVHD), cutaneous lupus, and others.

\section{Other autoimmune and autoinflammatory diseases}

Tofacitinib was first studied in the prevention of transplant rejection ${ }^{104,105}$, where it was efficacious but was also associated with an unacceptable risk of adverse events due to overimmunosuppression. Foremost among these were BK viremia, nephropathy, and posttransplant lymphoproliferative disease (PTLD). This may be due to the relatively high doses of tofacitinib used in the transplant trials (10-15 mg BID) and because the transplant patients were also treated with other potent immunomodulatory drugs (basiliximab, mycophenolate, sirolimus). Measuring post-dose serum concentrations to prevent overexposure may prevent such outcomes and lead jakinibs to be reevaluated in the prevention of transplant rejection ${ }^{106}$.

Baricitinib has been used in the treatment of autoinflammatory diseases, particularly those characterized by an interferon signature, or activation of interferon signaling genes ${ }^{107}$. Doses required have been high (mean dose $8.5 \mathrm{mg} /$ day), and treatment has been associated with BK viremia ${ }^{107,108}$, possibly due to over-immunosuppression required to control symptoms.

Jakinibs are also being used to treat other diseases associated with an interferon signature, namely systemic lupus erythematosus (SLE), dermatomyositis, and Sjogren's syndrome. For SLE, preclinical studies have been encouraging ${ }^{109}$. A Phase 1 tofacitinib trial (NCT02535689) and a Phase 2 baricitinib study (NCT02708095) are currently recruiting patients. Several cases of jakinib-responsive myositis ${ }^{110-112}$ have also been reported, and a clinical trial is planned (NCT03002649), although recruitment has not yet started.

Topical ophthalmic tofacitinib has also been tested in the treatment of dry eye disease, where results showed a trend towards improvement but were not significantly different from placebo ${ }^{113}$. It should be noted that patient selection may have contributed to lack of efficacy: dry eye is not always Sjogren's syndrome, or even immune-mediated ${ }^{114}$ and patient responses to topical cyclosporine, which is FDA-approved for keratoconjunctivitis sicca, were also poor ${ }^{113}$.

Given the number of immune-mediated diseases linked to activation of JAK-dependent cytokines, jakinibs are also being investigated for a host of other indications. Secondary hypereosinophilic syndrome (HES) ${ }^{98}$ is a group of disorders characterized by elevation of 
JAK-dependent cytokines including IL-4, IL-5, and IL-13. The IL-5 blocking agent mepolizumab is extremely effective in the treatment of HES ${ }^{115}$ and other eosinophilic diseases including allergic asthma ${ }^{10}$, although some subjects fail to respond completely, raising the possibility that blockade of multiple JAK-dependent cytokines might increase therapeutic efficacy. Preliminary reports support the efficacy of jakinibs in treating hypereosinophilic syndrome ${ }^{98}$, indicating that jakinibs might be useful in other diseases driven by the same cytokines, such as eosinophilic esophagitis allergy, and allergic asthma.

Tofacitinib has been reported as a treatment for vasculitis ${ }^{116}$ and has shown promising results in preclinical models ${ }^{117}$ of GVHD: a clinical trial using baricitinib is ongoing for this indication (NCT02759731). Another potential use could be multiple sclerosis (MS), a disease driven by pathogenic Th1 and Th17 subsets of CD4 T cells ${ }^{118}$. Tofacitinib can antagonize signaling downstream of IL-23, a pathogenic cytokine produced by Th17 cells. However, MS is a disease where the blockade of multiple cytokines could worsen pathogenesis: IFN- $\beta$ is used to treat patients; although its mechanism of action in this disease is still poorly understood. The IL-12/23 blocking agent ustekinumab, which is also thought to inhibit pathogenic Th17 cells, is not efficacious in MS, although preliminary results from a Phase 2a using the IL-17 blocking antibody secukinumab were encouraging 119. Further results will potentially clarify the role of pathogenic Th17 cells in MS pathogenesis ${ }^{118}$.

\section{Other diseases}

The role of JAK-dependent cytokines is increasingly being appreciated in several common diseases traditionally seen as driven by non-immunologic mechanisms. For example, preliminary data suggest that tofacitinib may be a potential treatment for diabetic nephropathy, where it appears to reduce albuminuria through blockade of renal inflammation ${ }^{120}$. Another such example is cardiovascular (CV) disease, which is increasingly seen as an inflammatory process ${ }^{121}$. Among other cytokines, IL-6 is associated with the pathogenesis of CV disease ${ }^{122}$, and the JAK-STAT pathway has been proposed as a potential therapeutic target in atherosclerosis 123 .

\section{The downside of JAK inhibition}

The adverse effects of jakinibs are largely predictable based on their biological functions as signal transducers for Type I and Type II cytokines. Because tofacitinib is the most widely used drug, its safety profile is the best characterized. However, the side effects of baricitinib and other nonselective jakinibs are similar, which is expected given the similar cytokine inhibition of the two drugs ${ }^{124}$.

\section{Infection}

It is not surprising that the most significant concerns regarding adverse effects have focused on the increased risk of infection. Indeed, review of the RA trials revealed that infections were commonly reported side effects $28-30,38,42,125$. Although most infections did not necessitate treatment discontinuation, severe and opportunistic infections such as tuberculosis and osteomyelitis were also reported. However, the risk of serious infections for 
jakinibs appear to be similar to that seen with biological agents ${ }^{42}$. A recent pooled metaanalysis confirms that tofacitinib may actually be less likely to increase infection risk than biological DMARDs ${ }^{125}$. Tofacitinib, baricitinib and peficitinib are associated with increased risk of Herpes zoster. Other serious viral infections have been associated with jakinibs, including a case of progressive multifocal leukoencephalopathy (PML) secondary to JC virus associated with ruxolitinib ${ }^{126}$. BK nephropathy was also reported in trials using tofacitinib to prevent rejection after kidney transplantation, in combination with mycophenolate mofetil or cyclosporine ${ }^{104,105}$. Inhibition of IFN signaling and effects on natural killer (NK) cells may underlie the increased risk of viral infections: NK cells are critical for antiviral defense, and their development and function both depend on JAK3dependent cytokines. Tofacitinib causes a dose-dependent decrease in NK cell counts although this effect may be temporary ${ }^{127128}$; careful studies probing tofacitinib-mediated alterations in NK cell function might better address these questions. Tofacitinib may also affect the development and function of plasmablasts ${ }^{129}$, also important in host defense against viral infection ${ }^{130}$. Tofacitinib does not affect response to influenza vaccine but decreases response to pneumococcal vaccination, particularly in combination with methotrexate, and temporary withdrawal does not restore responsiveness ${ }^{131}$. Thus, patients should be vaccinated against Herpes zoster and pneumococcal infections prior to starting tofacitinib, as with other biological DMARDs ${ }^{132}$.

\section{Anemia, leukopenia}

Because hematopoietic growth factors including erythropoietin signal through JAK2, cytopenias are commonly seen in patients treated with first generation pan-jakinibs. Neutropenia and anemia have been observed in many of the RA trials, particularly at higher doses of tofacitinib ${ }^{28-30,43,104}$. These alterations were typically well-tolerated and did not require treatment discontinuation. Baricitinib trials have shown similar results, with mild anemia and neutropenia in baricitinib-treated patients $51,53,133,134$. Subjects treated with peficitinib developed neutropenia but did not develop anemia; instead increases in hemoglobin were noted at higher doses of peficitinib, which may reflect resolution of inflammation-driven anemia of chronic disease. Unexpectedly, mild thrombocytosis has also been noted in baricitinib-treated patients, although not in those on tofacitinib. Because JAK2 blockade is an FDA-approved treatment for essential thrombocytosis ${ }^{14}$, one would rather expect thrombocytopenia as an adverse effect, and the reasons underlying treatmentassociated thrombocytosis are not clear.

\section{Lipids and cardiovascular disease}

Patients with autoimmune diseases, including RA and SLE, are at increased risk of cardiovascular (CV) disease, a major cause of mortality ${ }^{135-136}$. Psoriasis patients are also at risk for CV disease ${ }^{137}$ and metabolic syndrome, even compared to other inflammatory diseases $135,129,138$. The reasons for this are likely multifactorial: patients with autoimmune disease have a high prevalence of $\mathrm{CV}$ risk factors, yet autoimmune disease activity also increases CV disease risk $126,139,137,135,138,140$. JAK-dependent cytokines are thought to contribute to $\mathrm{CV}$ disease in autoimmunity, implying that JAK inhibition may actually reduce risk. Type I IFN promotes endothelial dysfunction ${ }^{141}$, while IL-6 affects lipid metabolism, drives insulin resistance, and promotes redistribution of serum lipids to peripheral tissues. 
This causes a lowering of serum lipid levels, which may paradoxically raise CV risk ${ }^{142,143}$. Indeed, patients treated with the IL-6 receptor inhibitor tocilizumab have increases in their serum lipid concentrations, but do not appear to have increased CV risk ${ }^{144}$.

Potentially related to blockade of signaling downstream of IL-6, treatment with nonselective jakinibs also increases serum low density lipoprotein (LDL) and high density lipoprotein (HDL) concentrations but does not alter the LDL:HDL ratio ${ }^{145}$. Review of pooled data from late-phase clinical trials indicates that tofacitinib, like tocilizumab, does not increase the risk of major cardiovascular events ${ }^{146,147}$. Yet patients with CV disease were excluded from the late-phase clinical trials, limiting the generalizability of this finding ${ }^{146}$. Moreover, tofacitinib reduces cholesterol ester catabolism, which is elevated in RA patients ${ }^{148}$. Tofacitinib also reduces arterial stiffness ${ }^{149}$ and lupus-associated vascular dysfunction ${ }^{109}$. Long-term data from Phase IV clinical trials is needed to determine whether JAK inhibition ultimately prevents, ameliorates, or exacerbates $\mathrm{CV}$ risk. Clearly, additional work in this area is warranted.

\section{GI perforation}

Patients treated with IL-6 receptor blockade also have a higher risk of lower gastrointestinal tract perforation than those treated with other biological DMARDs ${ }^{150}$, raising the concern that jakinibs may cause similar complications. Lower GI tract perforation was reported in several RA clinical trials, but thus far a significantly increased risk has not been seen in analysis of the late-phase clinical trial data nor has it been seen in the Phase 3 baricitinib trials ${ }^{69}$. The mechanisms by which jakinibs might increase risk of GI perforation are poorly defined but may be tied to the role of cytokines in gut barrier immunity. As detailed previously, IL-6 is critical to the differentiation of Th17 cells, and other type I/II cytokines including IL-22, IL-10 and IL-9 all have a protective role in intestinal barrier function ${ }^{151,152}$. The association of jakinibs with GI perforation once again highlights the multifaceted role of JAK-dependent cytokines in immune homeostasis and the importance of long-term monitoring for unexpected complications.

\section{Malignancy}

Aside from infection, a concern with immunosuppression is the potential for increased risk of malignancy. The possible mechanisms through which jakinibs might negatively impact immune responses to cancer include interference with $\mathrm{T}$ and NK cell function in immunosurveillance and the antineoplastic role of interferons. In patients receiving tofacitinib after kidney transplantation, the risk of post-transplant lymphoproliferative disease is indeed elevated in tofacitinib-treated patients ${ }^{105}$. Thus far, data from clinical trials and long-term extension studies in RA patients have not revealed an increased risk of hematologic or solid organ malignancy ${ }^{153}$. Further monitoring of tofacitinib-treated patients will be needed to determine whether long-term therapy confers any malignancy risk.

\section{Other side effects of jakinibs}

Other laboratory abnormalities in jakinib-treated patients included sporadic elevations in serum creatinine ${ }^{154}$, but this usually returned to baseline upon drug discontination ${ }^{42,43,154}$. Acute renal failure was infrequent and associated with concurrent serious illness, primarily 
infection $^{155}$; chronic renal dysfunction has not been reported as an adverse effect of jakinibs ${ }^{42,43,154}$. Some jakinibs have also been reported to cause elevations in transaminases 127. This is more common in patients being treated with tofacitinib and methotrexate in combination, and may necessitate dose adjustment or discontinuation ${ }^{35}$. In tofacitinibtreated rats, prolonged blockade of JAK2 downstream of prolactin caused testicular Leydig cell hyperplasia and adenoma ${ }^{156}$. Because human Leydig cells are not prolactindependent ${ }^{156}$, tofacitinib is not likely to cause testicular adenomas in patients. However, other long-term risks of hormone-like receptor blockade may become apparent from longterm extension studies.

\section{Next-generation jakinibs}

First-generation jakinibs block multiple JAKs and therefore inhibit the actions of a large variety of cytokines and several pan-JAK inhibitors continue to be developed (Table 3, Table 4). The rationale for this is that nonselective JAK inhibitors have already been proven safe, and that blockade of multiple JAKs might increase therapeutic efficacy. However, to minimize adverse effects, especially those arising from JAK2 inhibition, the generation of selective jakinibs could in principle maintain efficacy and improve safety. Moreover, novel mechanisms of achieving exquisite selectivity are emerging. All current jakinibs act through non-covalent interactions with the kinase domain, which is relatively conserved between JAK isoforms, but several novel compounds have been reported to bind covalently to nonconserved amino acid residues, leading to irreversible inhibition and reportedly high selectivity across the kinome. It is important, however, to appreciate that specificity as defined by doses used in vitro and in cell-based assays may lead to different conclusions compared to specificity as measured in patients treated with doses required for clinical efficacy.

\section{JAK1-selective inhibitors}

Filgotinib (Figure 3) is a JAK1 selective inhibitor with reduced activity against JAK2 157. Filgotinib was discovered after a kinase-focused high throughput library screen identified triazolopyridines as JAK1-selective catalytic inhibitors; this strategy has since been exploited to develop most other patented JAK1-selective drugs ${ }^{158,}$, 159,160. Further structureactivity relationships and structure-based design culminated in the development of filgotinib, which was effective in preclinical disease models ${ }^{158}$. Filgotinib was subsequently investigated in RA as monotherapy and in combination with MTX for patients with inadequate responses to MTX. In both settings, filgotinib displayed comparable efficacy to tofacitinib. Importantly, with respect to the purported lack of effect on JAK2, patients did not develop anemia; rather, a mild increase in hemoglobin was observed. However, patients did develop neutropenia, possibly due to inhibition of cytokines like G-CSF and IL-11 which signal through JAK1 and support myelopoiesis ${ }^{161}$. Other laboratory abnormalities were similar to those seen with tofacitinib, with dose-dependent increases in serum transaminases and lipids. Unlike tofacitinib, however, filgotinib increased the HDL:LDL ratio. Filgotinib is also the first jakinib to display clinically significant efficacy in Crohn's disease ${ }^{162}$, with a 2fold increase in clinical remission compared with placebo and rates similar to those seen 
with the standard-of-care therapy infliximab. Phase 3 trials are currently ongoing for both ulcerative colitis and Crohn's disease (NCT02914561, NCT02914522).

Upadacitinib (Figure 3) was developed using structural predictions that indicated potential for differential binding interactions outside the ATP-binding of JAK1 compared to JAK2, which is believed to provide JAK selectivity via an allosteric mechanism 163,164 . Upadacitinib is metabolized by CYP enzymes including CYP3A but can be taken with other CYP3A-metabolized drugs, including statins ${ }^{165}$. The efficacy of upadacitinib in RA was evaluated in the BALANCE1 and 2 Phase II clinical trials ${ }^{166,167}$, where patients who had failed either MTX or TNF inhibitors were treated with upadacitinib in combination with MTX. ACR20 responses were similar to those seen with nonselective drugs, and results were seen as early as 2 weeks after starting treatment. Adverse effects included infections, transient elevations in serum transaminases, and dose-dependent increases in serum lipids. Dose-dependent decreases in hemoglobin were noted in upadacitinib-treated patients, raising the possibility that at the higher doses needed to control autoimmune disease, the drug does inhibit JAK2 166,167, or that JAK1-dependent cytokines are necessary for normal erythropoiesis. Preliminary results from the phase 3 SELECT program have been encouraging in cDMARD-refractory RA patients; further trials are evaluating the drug in MTX-refractory, bDMARD-refractory, and treatment-naïve subjects ${ }^{168}$. Positive top-line results have also emerged from the CELEST trial in Crohn's disease, and trials are ongoing for atopic dermatitis (ClinicalTrials.gov NCT02782663, NCT02925117, NCT02819635).

Solcitinib (GLPG-0778, GSK-2586184, Figure 3) is a JAK1-selective inhibitor with a triazolopyridine scaffold and a acyclopropylamide in position 2 derived from GLPG0634 (which was originally discovered using high-throughput screening). Solcitinib was found to be efficacious for the treatment of plaque psoriasis ${ }^{169}$. However, during a phase II trial evaluating solcitinib as a treatment for SLE, six patients developed elevated liver enzymes, two of whom were diagnosed with drug reaction with eosinophilia and systemic symptoms (DRESS) ${ }^{170}$. These severe adverse events necessitated early termination of the trial and, in combination with the subsequent discovery of a statin drug-drug interaction, led to discontinuation of further development for the drug. PF-04965842 is another recently developed JAK1-selective drug; although clinical trials for lupus and plaque psoriasis were discontinued due to changes in the drug development portfolio, a Phase 2 trial for the treatment of atopic dermatitis is currently underway (NCT02780167).

\section{JAK3-selective inhibitors}

Decernotinib (Figure 3) is reported to be a JAK3-selective inhibitor developed to preserve JAK1 and JAK2 signaling, which, in principle, would eliminate non-immunologic adverse effects. This is because JAK3 transmits signals via common $\gamma$-chain associated cytokines, which prinicipally affect immune cells (Figure 2) ${ }^{16,17}$. In vitro assays indicate that decernotinib may have some activity against JAK1, however, and the drug has been reported to cause neutropenia in clinical trials 171172,173 . Thus, the degree of JAK3 selectivity has yet to be fully determined.

Decernotinib was discovered using high-throughput screening of a compound library ${ }^{174}$. It has comparable efficacy to tofacitinib for RA, both as monotherapy and in combination with 
methotrexate $172,173,175$. These results were encouraging, but the development of neutropenia in decernotinib-treated patients was puzzling. Another major concern arises from the fact that decernotinib alone amongst the JAK inhibitors is a potent inhibitor of CYP3A4 ${ }^{176}$. Because CYP3A4 is the predominant hepatic CYP, it metabolizes over half of the medications currently used to treat human disease, including high-potency statins. This drug-drug interaction could present a limitation to decernotinib use.

Several novel compounds are reported to bind covalently to nonconserved amino acid residues, leading to irreversible inhibition and reportedly high selectivity across the kinome 177. Because these are both new features, it will be critical to carefully assess the risks and benefits of each as such compounds proceed to clinical development and to assess whether the reported in vitro selectivity translates to in vivo efficacy and selectivity. PF-06651600 is the only irreversible covalent JAK3 inhibitor being used in clinical trials: it was developed by modifying the structure of tofacitinib to optimize selectivity and allow covalent binding (Figure 3). PF-06651600 is being tested for the treatment of RA and alopecia areata, and a trial is planned for ulcerative colitis 178 (NCT02969044, NCT02974868, NCT02958865).

\section{TYK2-selective inhibitors}

TYK2-selective inhibitors have been developed ${ }^{179180}$ with the goal of blocking signaling downstream of the cytokines IL-6, IL-12, and IL-23, all of which are implicated in the pathogenesis of various autoimmune diseases ${ }^{1}$. Investigational TYK2 inhibitors have shown exciting preclinical efficacy in models of psoriasis, lupus, and inflammatory bowel disease 179,181. BMS986165 is a TYK2 inhibitor that was discovered using a phenotypic screen of kinase inhibitors to identify ligands of the TYK2 pseudokinase domain. The pseudokinase domain was then targeted based on crystallographic structural information, resulting in allosteric inhibition ${ }^{182181}$. BMS986165 ameliorates disease in preclinical models of SLE and IBD, and a phase 2 trial is currently ongoing for the treatment of psoriasis 181 (NCT02931838). Other TYK2 inhibitors, such as NDI-031232 and NDI-031407, were developed using structure-based design and are being tested in preclinical models 179,180 . Finally, several new inhibitors in phase 1 trials inhibit both JAK1 and TYK2. PF-06700841 was developed using a structurally enabled program in combination with high-throughput screening, and is being tested in psoriasis, and alopecia areata, with plans for a trial in IBD. 183 (NCT02969018, 02974868, 02958865). SAR-20347 was discovered using highthroughput computational screening followed by secondary screening against a panel of 291 kinases, and is effective in mouse models of inflammatory skin disease ${ }^{184}$. Given differences between in vitro and in vivo selectivity of other jakinibs, this and other trials will determine whether TYK2-blockers are selective in clinical practice, and how selectivity might affect outcomes.

\section{JAK inhibitors that also inhibit other kinases}

Several JAK inhibitors that have been tested for immune-mediated disease also inhibit nonJAK kinases, most notably SYK (spleen tyrosine kinase). SYK is a critical kinase used by a number of multichain immune recognition receptors ${ }^{185}$. In principle, targeting SYK along with JAKs could enhance efficacy by broadening the signaling pathways that are blocked; however, this could also be associated with exaggerated adverse events. The SYK inhibitor 
fostamitinib was effective in the treatment of RA but was associated with hypertension. Fostamitinib is currently being evaluated for the immune-mediated diseases Autoimmune Hemolytic Anemia (AIHA), Immune-mediated Thrombocytopenic Purpura (ITP), and IgA Nephropathy (NCT 02076412, 02612558, 02077192, 02112838) ${ }^{186}$. The topical JAK/SYK inhibitor R348 did not meet its primary endpoints for the treatment of dry eye disease and is no longer being pursued.. R333, a topical drug that is the active metabolite of R348, was tested for the treatment of discoid lupus erythematosus but also failed to meet its primary endpoint. Another JAK/SYK inhibitor, cerdulatinib, was discovered using extensive structure-activity relationship studies and has demonstrated efficacy in an animal arthritis model $^{187}$.

SB-1578 is an inhibitor of JAK2, CSF-1 (colony stimulating factor 1, c-Fms) receptor, and FLT3 (Fms Related Tyrosine Kinase 3). CSF-1 receptor is a tyrosine kinase that promotes the proliferation and differentiation of myeloid cells, and FLT3 is essential for hematopoiesis 188,189. FLT3 and CSF-1 receptor mutations cause hematopoietic malignancy, and both kinases are also implicated in RA pathogenesis. As for combinations JAK/SYK inhibitors, simultaneous blockade of three discrete signaling pathways with agents like SB-1578 might increase efficacy but could also worsen adverse effects ${ }^{190}$. SB-1578 was developed by modifying the structure of pacritinib, a multikinase inhibitor under investigation for myelofibrosis and various malignancies, to achieve an improved therapeutic window ${ }^{191}$. SB-1578 was effective in the preclinical model of collagen-induced arthritis ${ }^{190}$. A Phase I trial in healthy subjects was completed in 2012, but results were not made available and further development has not taken place (NCT01235871).

\section{Future directions}

The last decade has witnessed an explosion of data regarding the efficacy of selective and nonselective jakinibs in the treatment of autoimmunity. In many respects, the success of jakinibs based on genetic models was predictable. What was less predictable was their relative safety (Table 5). Jakinibs therefore serve as an interesting model for other drugs designed to target key intracellular signaling pathways.

Still critical questions with immediate clinical relevance remain unanswered, providing several areas of research for future investigators. Among the most exciting of these is the possibility that tofacitinib may be efficacious for debilitating, treatment-refractory autoimmune diseases. Immune-mediated diseases such as SLE, IBD, and dermatomyositis have fewer treatment choices than RA and psoriasis. With multiple early-phase clinical trials in such diseases underway, the next few years should begin to establish the efficacy and safety of various JAK inhibitors in such diseases (NCT 03159936, 0253568902708095 , 03002649, 03026504).

Next, the benefits, risks, and optimal mechanisms for achieving in vivo selectivity remain elusive. While many next-generation Jakinibs are reasonably selective in vitro, their selectivity in the clinical arena is not as fully characterized and remains to be proven. Moreover, while current studies indicate that selective and pan-jakinibs are equally effective for RA, this may not be true for other immune-mediated diseases. For example, the JAK1- 
selective filgotinib significantly ameliorates $\mathrm{CD}$, whereas tofacitinib does not. This raises the question as to which cytokines are being differentially inhibited by filgotinib and tofacitinib, and how various JAK isoforms contribute to CD pathophysiology. It also raises the prospect that selective blockade of one JAK isoform over another may be sufficient or even advantageous in certain immune-mediated diseases ${ }^{192}$, while blockade of multiple JAKs may be necessary in other settings ${ }^{193}$. Moreover, other kinase inhibitors have activity against JAKs ${ }^{194}$, raising the prospect that wider blockade of multiple signaling pathways may provide additional therapeutic benefit - although the risks must be carefully balanced. As the spectrum of jakinib-responsive disease expands, perhaps even including IL-13 driven fibrotic diseases such as berylliosis ${ }^{195}$, the risks and benefits of JAK isoform selectivity in different rheumatic diseases will become increasingly clear and will perhaps contribute to our understanding of disease pathogenesis.

For jakinib-responsive diseases, it is still unknown which patients would derive the most benefit from JAK blockade: the current ACR guidelines recommend tofacitinib for the treatment of cDMARD-refractory established RA but do not distinguish between tofacitinib and bDMARDs. Clearly, the field needs more rational treatment selection: in clinical trials $30-40 \%$ of RA patients invariably fail to respond to therapy. While most RA patients can be successfully treated with an FDA-approved agent, we are currently unable to predict which therapy will be most effective for a particular patient. This may be because most polygenic autoimmune diseases are heterogeneous ${ }^{1}$, such that JAK-dependent cytokines might drive disease in a large subset of patients, while other cytokines could be more important for different subgroups. A vigorous search is currently underway to identify biomarkers that could predict response to various immunomodulatory agents, including jakinibs. With improved success in treating diseases like RA, the prospect emerges of cure or long term remission. Many believe that this will require more aggressive, early treatment of patients. One might expect that trials employing jakinibs in early RA will be considered. In addition, one can imagine tapering patients off methotrexate when disease comes under control; this too should be investigated in clinical trials.

Another area that remains to be established is the optimal dosing regimen for jakinibs. Currently, all clinical trials use an identical dose for induction of remission and for maintenance therapy. However, preclinical data suggests that chronically treated cells become less responsive to JAK-dependent cytokines, or chronically "inhibited", even after a washout period ${ }^{196}$ when they are not being treated with Jakinibs. This raises the possibility that jakinibs could be dosed aggressively to induce remission, then tapered to a much lower dose for maintenance therapy ${ }^{196}$. This is already the regimen used in canines, where oclacitinib is dosed twice daily for up to 14 days and once daily thereafter.

Moreover, some autoimmune diseases present with limited cutaneous, mucosal, or ocular involvement. Clearly, the possibility of treating such diseases with topical formulations and sparing systemic adverse effects is very exciting. While some topical formulations of tofacitinib and ruxolitinib have been investigated in preliminary studies, these studies are still in their infancy. 
Similarly, the risks and benefits of jakinibs as monotherapy vs. combination therapy with other immunomodulators such as MTX or even biologics ${ }^{197}$ remain incompletely characterized. As the renal transplant studies have shown, this strategy is not without risk, but could potentially be managed using a serum concentration-based dose escalation protocol or immunological functional studies to gauge early response to therapy. As with corticosteroids, there might be a role for bDMARDs with long half-lives as maintenance therapy, whereas potent tsDMARDs with short half-lives could be used for breakthrough activity. This strategy could be particularly relevant to catastrophic flares of systemic autoimmune diseases, where current standard of care is to profoundly immunosuppress patients and induce remission, then follow up with less toxic consolidation and maintenance therapy.

Along these lines, our understanding of immunopathology is increasingly becoming more refined as we begin to incorporate recent discoveries about the role of noncoding, regulatory DNA elements ${ }^{198}$. Such elements may be relatively close to genes but can also be far away. Moreover, some key genes are surrounded by dense regions of regulatory elements termed "superenhancers". In T cells, genes with superenhancer structure seem preferentially affected by jakinibs ${ }^{198}$. As our understanding of the immense numbers of regulatory elements becomes clearer, physicians may be able to fine-tune the expression of critical disease regulators, rather than simply turning them on or off; much like an acoustic editor in a recording studio "adjusts the gain" of faders on a mixing console. In this way, the effect of immunomodulation might be optimized and adverse effects minimized. In this way, the effect of immunomodulation might be optimized and adverse effects minimized.

Finally, a host of novel jakinibs are being developed (Table 4), with at least 95 patented candidates ${ }^{159,160}$. Many are analogs of FDA-approved compounds, but some have achieved unprecedented selectivity by covalently targeting nonconserved residues at the kinase domain. As the field evolves, jakinibs thus continue demonstrating clinical efficacy as immunomodulators, while also providing critical insights into the mechanisms driving immune-mediated disease.

\section{References}

1. Schwartz DM, Bonelli M, Gadina M \& O'Shea JJ Type I/II cytokines, JAKs, and new strategies for treating autoimmune diseases. Nat Rev Rheumatol 12, 25-36, doi:10.1038/nrrheum.2015.167 (2016). [PubMed: 26633291]

2. Singh JA et al. Biologics or tofacitinib for rheumatoid arthritis in incomplete responders to methotrexate or other traditional disease-modifying anti-rheumatic drugs: a systematic review and network meta-analysis. Cochrane Database Syst Rev, CD012183, doi:10.1002/14651858.CD012183 (2016).

3. Kalliolias GD \& Ivashkiv LB TNF biology, pathogenic mechanisms and emerging therapeutic strategies. Nat Rev Rheumatol 12, 49-62, doi:10.1038/nrrheum.2015.169 (2016). [PubMed: 26656660]

4. Duarte JH Spondyloarthropathies: IL-17A blockade ameliorates ankylosing spondylitis. Nat Rev Rheumatol 12, 72, doi:10.1038/nrrheum.2016.7 (2016).

5. Schett G, Dayer JM \& Manger B Interleukin-1 function and role in rheumatic disease. Nat Rev Rheumatol 12, 14-24, doi:10.1038/nrrheum.2016.166 (2016). [PubMed: 26656658] 
6. Canavan TN, Elmets CA, Cantrell WL, Evans JM \& Elewski BE Anti-IL-17 Medications Used in the Treatment of Plaque Psoriasis and Psoriatic Arthritis: A Comprehensive Review. Am J Clin Dermatol 17, 33-47, doi:10.1007/s40257-015-0162-4 (2016). [PubMed: 26649440]

7. Calabrese LH \& Rose-John S IL-6 biology: implications for clinical targeting in rheumatic disease. Nat Rev Rheumatol 10, 720-727, doi:10.1038/nrrheum.2014.127 (2014). [PubMed: 25136784]

8. Pepys MB \& Hirschfield GM C-reactive protein: a critical update. Journal of Clinical Investigation 111, 1805-1812, doi:10.1172/jci200318921 (2003). [PubMed: 12813013]

9. Feagan BG et al. Ustekinumab as Induction and Maintenance Therapy for Crohn's Disease. The New England journal of medicine 375, 1946-1960, doi:10.1056/NEJMoa1602773 (2016). [PubMed: 27959607]

10. Ortega HG et al. Mepolizumab treatment in patients with severe eosinophilic asthma. The New England journal of medicine 371, 1198-1207, doi:10.1056/NEJMoa1403290 (2014). [PubMed: 25199059]

11. Hanania NA et al. Efficacy and safety of lebrikizumab in patients with uncontrolled asthma (LAVOLTA I and LAVOLTA II): replicate, phase 3, randomised, double-blind, placebo-controlled trials. The Lancet Respiratory Medicine 4, 781-796, doi:10.1016/s2213-2600(16)30265-x (2016). [PubMed: 27616196]

12. Wenzel S et al. Dupilumab efficacy and safety in adults with uncontrolled persistent asthma despite use of medium-to-high-dose inhaled corticosteroids plus a long-acting $\beta 2$ agonist: a randomised double-blind placebo-controlled pivotal phase $2 \mathrm{~b}$ dose-ranging trial. The Lancet $388,31-44$, doi: 10.1016/s0140-6736(16)30307-5 (2016).

13. O'Shea JJ, Holland SM \& Staudt LM JAKs and STATs in immunity, immunodeficiency, and cancer. The New England journal of medicine 368, 161-170, doi:10.1056/NEJMra1202117 (2013). [PubMed: 23301733]

14. O'Shea JJ et al. The JAK-STAT pathway: impact on human disease and therapeutic intervention. Annu Rev Med 66, 311-328, doi:10.1146/annurev-med-051113-024537 (2015). [PubMed: 25587654]

15. Ross SH et al. Phosphoproteomic Analyses of Interleukin 2 Signaling Reveal Integrated JAK Kinase-Dependent and -Independent Networks in CD8(+) T Cells. Immunity 45, 685-700, doi: 10.1016/j.immuni.2016.07.022 (2016). [PubMed: 27566939]

16. Macchi $\mathrm{P}$ et al. Mutations of Jak-3 gene in patients with autosomal severe combined immune deficiency (SCID). Nature 377, 65-68, doi:10.1038/377065a0 (1995). [PubMed: 7659163]

17. Russell SM et al. Mutation of Jak3 in a patient with SCID: essential role of Jak3 in lymphoid development. Science 270, 797-800 (1995). [PubMed: 7481768]

18. Druker BJ et al. Efficacy and safety of a specific inhibitor of the BCR-ABL tyrosine kinase in chronic myeloid leukemia. The New England journal of medicine 344, 1031-1037, doi:10.1056/ NEJM200104053441401 (2001). [PubMed: 11287972]

19. Rask-Andersen M, Zhang J, Fabbro D \& Schioth HB Advances in kinase targeting: current clinical use and clinical trials. Trends Pharmacol Sci 35, 604-620, doi:10.1016/j.tips.2014.09.007 (2014). [PubMed: 25312588]

20. Herrera AF \& Jacobsen ED Ibrutinib for the treatment of mantle cell lymphoma. Clin Cancer Res 20, 5365-5371, doi:10.1158/1078-0432.CCR-14-0010 (2014). [PubMed: 25361916]

21. Lippert $\mathrm{E}$ et al. The JAK2-V617F mutation is frequently present at diagnosis in patients with essential thrombocythemia and polycythemia vera. Blood 108, 1865-1867, doi:10.1182/ blood-2006-01-013540 (2006). [PubMed: 16728702]

22. Verstovsek S et al. A double-blind, placebo-controlled trial of ruxolitinib for myelofibrosis. The New England journal of medicine 366, 799-807, doi:10.1056/NEJMoa1110557 (2012). [PubMed: 22375971]

23. Harrison $\mathrm{C}$ et al. JAK inhibition with ruxolitinib versus best available therapy for myelofibrosis. The New England journal of medicine 366, 787-798, doi:10.1056/NEJMoa1110556 (2012). [PubMed: 22375970]

24. Waldmann TA \& Chen J Disorders of the JAK/STAT Pathway in T Cell Lymphoma Pathogenesis: Implications for Immunotherapy. Annu Rev Immunol, doi:10.1146/annurevimmunol-110416-120628 (2017). 
25. Kudlacz E et al. The Novel JAK-3 Inhibitor CP-690550 Is a Potent Immunosuppressive Agent in Various Murine Models. American Journal of Transplantation 4, 51-57, doi:10.1046/j. 1600-6143.2003.00281.x (2004).

26. Ghoreschi $\mathrm{K}$ et al. Modulation of innate and adaptive immune responses by tofacitinib (CP-690,550). J Immunol 186, 4234-4243, doi:10.4049/jimmunol.1003668 (2011). [PubMed: 21383241]

27. Milici AJ, Kudlacz EM, Audoly L, Zwillich S \& Changelian P Cartilage preservation by inhibition of Janus kinase 3 in two rodent models of rheumatoid arthritis. Arthritis Res Ther 10, R14, doi: 10.1186/ar2365 (2008). [PubMed: 18234077]

28. Lee EB et al. Tofacitinib versus methotrexate in rheumatoid arthritis. The New England journal of medicine 370, 2377-2386, doi:10.1056/NEJMoa1310476 (2014). [PubMed: 24941177]

29. Burmester GR et al. Tofacitinib (CP-690,550) in combination with methotrexate in patients with active rheumatoid arthritis with an inadequate response to tumour necrosis factor inhibitors: a randomised phase 3 trial. The Lancet 381, 451-460, doi:10.1016/s0140-6736(12)61424-x (2013).

30. van Vollenhoven RF et al. Tofacitinib or adalimumab versus placebo in rheumatoid arthritis. The New England journal of medicine 367, 508-519, doi:10.1056/NEJMoa1112072 (2012). [PubMed: 22873531]

31. Lee EB, Fleischmann R \& Hall S Radiographic, clinical and functional comparison of tofacitinib monotherapy versus methotrexate in methotrexate-naïve patients with rheumatoid arthritis. Arthritis Rheum 64, S1049 (2012).

32. Kremer JM et al. Tofacitinib (cp-690,550), an oral JAK inhibitor, in combination with traditional DMARDs: phase 3 study in patients with active rheumatoid arthritis with inadequate response to DMARDs. Ann Rheum Dis 70, 170 (2011).

33. Fleischmann RM et al. Efficacy of tofacitinib monotherapy in methotrexate-naive patients with early or established rheumatoid arthritis. RMD Open 2, e000262, doi:10.1136/ rmdopen-2016-000262 (2016). [PubMed: 27493790]

34. Fleischmann R et al. Placebo-controlled trial of tofacitinib monotherapy in rheumatoid arthritis. The New England journal of medicine 367, 495-507, doi:10.1056/NEJMoa1109071 (2012). [PubMed: 22873530]

35. Conaghan PG et al. Comparing the effects of tofacitinib, methotrexate and the combination, on bone marrow oedema, synovitis and bone erosion in methotrexate-naive, early active rheumatoid arthritis: results of an exploratory randomised MRI study incorporating semiquantitative and quantitative techniques. Ann Rheum Dis 75, 1024-1033, doi:10.1136/annrheumdis-2015-208267 (2016). [PubMed: 27002108]

36. Strand V et al. Tofacitinib with methotrexate in third-line treatment of patients with active rheumatoid arthritis: patient-reported outcomes from a phase III trial. Arthritis care \& research 67, 475-483, doi:10.1002/acr.22453 (2015). [PubMed: 25186034]

37. Charles-Schoeman $\mathrm{C}$ et al. Efficacy and safety of tofacitinib following inadequate response to conventional synthetic or biological disease-modifying antirheumatic drugs. Ann Rheum Dis 75, 1293-1301, doi:10.1136/annrheumdis-2014-207178 (2016). [PubMed: 26275429]

38. van der Heijde D et al. Tofacitinib (CP-690,550) in patients with rheumatoid arthritis receiving methotrexate: twelve-month data from a twenty-four-month phase III randomized radiographic study. Arthritis Rheum 65, 559-570, doi:10.1002/art.37816 (2013). [PubMed: 23348607]

39. Landewe $\mathrm{RB}$ et al. Is radiographic progression in modern rheumatoid arthritis trials still a robust outcome? Experience from tofacitinib clinical trials. Arthritis Res Ther 18, 212, doi:10.1186/ s13075-016-1106-y (2016). [PubMed: 27663201]

40. Administration, F. a. D (2012).

41. Yamanaka $\mathrm{H}$ et al. Tofacitinib, an oral Janus kinase inhibitor, as monotherapy or with background methotrexate, in Japanese patients with rheumatoid arthritis: an open-label, long-term extension study. Arthritis Res Ther 18, 34, doi:10.1186/s13075-016-0932-2 (2016). [PubMed: 26818974]

42. He Y et al. Efficacy and safety of tofacitinib in the treatment of rheumatoid arthritis: a systematic review and meta-analysis. BMC musculoskeletal disorders 14, 298, doi: 10.1186/1471-2474-14-298 (2013). [PubMed: 24139404] 
43. Wollenhaupt J et al. Safety and efficacy of tofacitinib, an oral janus kinase inhibitor, for the treatment of rheumatoid arthritis in open-label, longterm extension studies. J Rheumatol 41, 837852, doi:10.3899/jrheum.130683 (2014). [PubMed: 24692527]

44. Fleischmann R et al. Efficacy and safety of tofacitinib in patients with active rheumatoid arthritis: review of key Phase 2 studies. Int J Rheum Dis, doi:10.1111/1756-185X.12901 (2016).

45. Smolen JS et al. Remission Rates with Tofacitinib Treatment in Rheumatoid Arthritis: A Comparison of Various Remission Criteria. Arthritis Rheumatol, doi:10.1002/art.39996 (2016).

46. Wang J, Devenport J, Low JM, Yu D \& Hitraya E Relationship Between Baseline and Early Changes in C-Reactive Protein and Interleukin-6 Levels and Clinical Response to Tocilizumab in Rheumatoid Arthritis. Arthritis care \& research 68, 882-885, doi:10.1002/acr.22765 (2016). [PubMed: 26473986]

47. Strand V et al. Tofacitinib versus methotrexate in rheumatoid arthritis: patient-reported outcomes from the randomised phase III ORAL Start trial. RMD Open 2, e000308, doi:10.1136/ rmdopen-2016-000308 (2016). [PubMed: 27752357]

48. Strand V et al. Effects of tofacitinib monotherapy on patient-reported outcomes in a randomized phase 3 study of patients with active rheumatoid arthritis and inadequate responses to DMARDs. Arthritis Res Ther 17, 307, doi:10.1186/s13075-015-0825-9 (2015). [PubMed: 26530039]

49. Lamba M et al. Extended-Release Once-Daily Formulation of Tofacitinib: Evaluation of Pharmacokinetics Compared With Immediate-Release Tofacitinib and Impact of Food. J Clin Pharmacol 56, 1362-1371, doi:10.1002/jcph.734 (2016). [PubMed: 26970526]

50. Shi JG et al. The pharmacokinetics, pharmacodynamics, and safety of baricitinib, an oral JAK $1 / 2$ inhibitor, in healthy volunteers. J Clin Pharmacol 54, 1354-1361, doi:10.1002/jcph.354 (2014). [PubMed: 24965573]

51. Dougados $\mathrm{M}$ et al. Baricitinib in patients with inadequate response or intolerance to conventional synthetic DMARDs: results from the RA-BUILD study. Ann Rheum Dis 76, 88-95, doi:10.1136/ annrheumdis-2016-210094 (2017). [PubMed: 27689735]

52. Fleischmann R et al. Baricitinib, Methotrexate, or Combination in Patients With Rheumatoid Arthritis and No or Limited Prior Disease-Modifying Antirheumatic Drug Treatment. Arthritis Rheumatol 69, 506-517, doi:10.1002/art.39953 (2017). [PubMed: 27723271]

53. Genovese MC et al. Baricitinib in Patients with Refractory Rheumatoid Arthritis. The New England journal of medicine 374, 1243-1252, doi:10.1056/NEJMoa1507247 (2016). [PubMed: 27028914]

54. Taylor PC et al. Baricitinib versus Placebo or Adalimumab in Rheumatoid Arthritis. The New England journal of medicine 376, 652-662, doi:10.1056/NEJMoa1608345 (2017). [PubMed: 28199814]

55. Lilly E (Business Wire, Business Wire, 2017).

56. Takeuchi $\mathrm{T}$ et al. Efficacy and safety of the oral Janus kinase inhibitor peficitinib (ASP015K) monotherapy in patients with moderate to severe rheumatoid arthritis in Japan: a 12-week, randomised, double-blind, placebo-controlled phase IIb study. Ann Rheum Dis 75, 1057-1064, doi:10.1136/annrheumdis-2015-208279 (2016). [PubMed: 26672064]

57. Kivitz AJ et al. Peficitinib, a JAK inhibitor, in the treatment of moderate-to-severe rheumatoid arthritis in methotrexate-inadequate responders. Arthritis Rheumatol, doi:10.1002/art.39955 (2016).

58. Mease PJ et al. Efficacy and Safety of Tofacitinib, an Oral Janus Kinase Inhibitor, or Adalimumab in Patients with Active Psoriatic Arthritis and an Inadequate Response to Conventional Synthetic Dmards: A Randomized, Placebo-Controlled, Phase 3 Trial [abstract]. Arthritis and Rheumatism 68 (2016).

59. Gao W et al. Tofacitinib regulates synovial inflammation in psoriatic arthritis, inhibiting STAT activation and induction of negative feedback inhibitors. Ann Rheum Dis 75, 311-315, doi: 10.1136/annrheumdis-2014-207201 (2016). [PubMed: 26353790]

60. van der Heijde D et al. Tofacitinib in Patients with Ankylosing Spondylitis: A Phase 2, 16-Week, Randomized, Placebo-Controlled, Dose-Ranging Study [abstract]. Arthritis Rheum 67 (2015). 
61. van der Heijde D et al. OP0002 Tofacitinib in Patients with Ankylosing Spondylitis: A Phase 2, 16Week, Randomised, Placebo-Controlled, Dose-Ranging Study. Annals of the Rheumatic Diseases 75, 52.52-53, doi:10.1136/annrheumdis-2016-eular.1847 (2016). [PubMed: 25873634]

62. Tseng B et al. Tofacitinib Response in Juvenile Idiopathic Arthritis (JIA) and Collagenous Colitis. J Clin Rheumatol 22, 446-448, doi:10.1097/RHU.0000000000000456 (2016). [PubMed: 27870773]

63. Sandborn WJ et al. in European Crohn's and Colitis Organization (2016).

64. Sandborn WJ et al. A Phase 2 Study of Tofacitinib, an Oral Janus Kinase Inhibitor, in Patients With Crohn's Disease. Clinical gastroenterology and hepatology : the official clinical practice journal of the American Gastroenterological Association, doi:10.1016/j.cgh.2014.01.029 (2014).

65. Panes J et al. Tofacitinib for induction and maintenance therapy of Crohn's disease: results of two phase IIb randomised placebo-controlled trials. Gut, doi:10.1136/gutjnl-2016-312735 (2017).

66. Nalleweg $\mathrm{N}$ et al. IL-9 and its receptor are predominantly involved in the pathogenesis of UC. Gut 64, 743-755, doi:10.1136/gutjnl-2013-305947 (2015). [PubMed: 24957265]

67. Rutz S, Wang X \& Ouyang W The IL-20 subfamily of cytokines--from host defence to tissue homeostasis. Nature reviews. Immunology 14, 783-795, doi:10.1038/nri3766 (2014).

68. Gerlach K et al. TH9 cells that express the transcription factor PU.1 drive T cell-mediated colitis via IL-9 receptor signaling in intestinal epithelial cells. Nat Immunol 15, 676-686, doi:10.1038/ni. 2920 (2014). [PubMed: 24908389]

69. Hueber W et al. Secukinumab, a human anti-IL-17A monoclonal antibody, for moderate to severe Crohn's disease: unexpected results of a randomised, double-blind placebo-controlled trial. Gut 61, 1693-1700, doi:10.1136/gutjnl-2011-301668 (2012). [PubMed: 22595313]

70. Leung JM et al. IL-22-producing CD4+ cells are depleted in actively inflamed colitis tissue. Mucosal Immunol 7, 124-133, doi:10.1038/mi.2013.31 (2014). [PubMed: 23695510]

71. Casanova JL \& Abel L Revisiting Crohn's disease as a primary immunodeficiency of macrophages. J Exp Med 206, 1839-1843, doi:10.1084/jem.20091683 (2009). [PubMed: 19687225]

72. Bissonnette $\mathrm{R}$ et al. Tofacitinib withdrawal and retreatment in moderate-to-severe chronic plaque psoriasis: a randomized controlled trial. Br J Dermatol 172, 1395-1406, doi:10.1111/bjd.13551 (2015). [PubMed: 25418186]

73. Chiricozzi A et al. Tofacitinib for the treatment of moderate-to-severe psoriasis. Expert Rev Clin Immunol 11, 443-455, doi:10.1586/1744666X.2015.1013534 (2015). [PubMed: 25666451]

74. Krueger $\mathrm{J}$ et al. Tofacitinib attenuates pathologic immune pathways in patients with psoriasis: A randomized phase 2 study. The Journal of allergy and clinical immunology 137, 1079-1090, doi: 10.1016/j.jaci.2015.12.1318 (2016). [PubMed: 27059729]

75. Bachelez $\mathrm{H}$ et al. Tofacitinib versus etanercept or placebo in moderate-to-severe chronic plaque psoriasis: a phase 3 randomised non-inferiority trial. The Lancet, doi:10.1016/ s0140-6736(14)62113-9 (2015).

76. Berkrot B in Reuters (2015).

77. Papp KA et al. A randomized phase $2 b$ trial of baricitinib, an oral Janus kinase (JAK) 1/JAK2 inhibitor, in patients with moderate-to-severe psoriasis. Br J Dermatol 174, 1266-1276, doi: 10.1111/bjd.14403 (2016). [PubMed: 26800231]

78. Papp K et al. A phase $2 \mathrm{a}$ randomized, double-blind, placebo-controlled, sequential dose-escalation study to evaluate the efficacy and safety of ASP015K, a novel Janus kinase inhibitor, in patients with moderate-to-severe psoriasis. Br J Dermatol 173, 767-776, doi:10.1111/bjd.13745 (2015). [PubMed: 25704750]

79. Papp KA et al. Treatment of plaque psoriasis with an ointment formulation of the Janus kinase inhibitor, tofacitinib: a Phase 2b randomized clinical trial. BMC Dermatol 16, 15, doi:10.1186/ s12895-016-0051-4 (2016). [PubMed: 27716172]

80. Punwani $\mathrm{N}$ et al. Preliminary clinical activity of a topical JAK1/2 inhibitor in the treatment of psoriasis. J Am Acad Dermatol 67, 658-664, doi:10.1016/j.jaad.2011.12.018 (2012). [PubMed: 22281165]

81. Punwani N et al. Downmodulation of key inflammatory cell markers with a topical Janus kinase 1/2 inhibitor. Br J Dermatol 173, 989-997, doi:10.1111/bjd.13994 (2015). [PubMed: 26123031] 
82. Xing L et al. Alopecia areata is driven by cytotoxic T lymphocytes and is reversed by JAK inhibition. Nat Med 20, 1043-1049, doi:10.1038/nm.3645 (2014). [PubMed: 25129481]

83. Liu LY, Craiglow BG, Dai F \& King BA Tofacitinib for the treatment of severe alopecia areata and variants: A study of 90 patients. J Am Acad Dermatol 76, 22-28, doi:10.1016/j.jaad.2016.09.007 (2017). [PubMed: 27816293]

84. Craiglow BG, Liu LY \& King BA Tofacitinib for the treatment of alopecia areata and variants in adolescents. J Am Acad Dermatol 76, 29-32, doi:10.1016/j.jaad.2016.09.006 (2017). [PubMed: 27816292]

85. Scheinberg M \& Ferreira SB Reversal of Alopecia Universalis by Tofacitinib: A Case Report. Ann Intern Med 165, 750-751, doi:10.7326/L16-0125 (2016). [PubMed: 27842401]

86. Kennedy Crispin M et al. Safety and efficacy of the JAK inhibitor tofacitinib citrate in patients with alopecia areata. JCI Insight 1, e89776, doi:10.1172/jci.insight.89776 (2016). [PubMed: 27699252]

87. Pieri L, Guglielmelli P \& Vannucchi AM Ruxolitinib-induced reversal of alopecia universalis in a patient with essential thrombocythemia. Am J Hematol 90, 82-83, doi:10.1002/ajh.23871 (2015). [PubMed: 25307179]

88. Jabbari A et al. Reversal of Alopecia Areata Following Treatment With the JAK1/2 Inhibitor Baricitinib. EBioMedicine 2, 351-355, doi:10.1016/j.ebiom.2015.02.015 (2015). [PubMed: 26137574]

89. Gupta AK, Carviel JL \& Abramovits W Efficacy of tofacitinib in treatment of alopecia universalis in two patients. J Eur Acad Dermatol Venereol 30, 1373-1378, doi:10.1111/jdv.13598 (2016). [PubMed: 27306107]

90. Anzengruber F et al. Transient Efficacy of Tofacitinib in Alopecia Areata Universalis. Case Rep Dermatol 8, 102-106, doi:10.1159/000445182 (2016). [PubMed: 27194979]

91. Craiglow BG, Tavares D \& King BA Topical Ruxolitinib for the Treatment of Alopecia Universalis. JAMA Dermatol 152, 490-491, doi:10.1001/jamadermatol.2015.4445 (2016). [PubMed: 26649829]

92. Cosgrove SB et al. A blinded, randomized, placebo-controlled trial of the efficacy and safety of the Janus kinase inhibitor oclacitinib (Apoquel(R)) in client-owned dogs with atopic dermatitis. Vet Dermatol 24, 587-597, e141-582, doi:10.1111/vde.12088 (2013). [PubMed: 24581322]

93. Gonzales AJ et al. Oclacitinib (APOQUEL((R))) is a novel Janus kinase inhibitor with activity against cytokines involved in allergy. J Vet Pharmacol Ther 37, 317-324, doi:10.1111/jvp.12101 (2014). [PubMed: 24495176]

94. Amano $\mathrm{W}$ et al. The Janus kinase inhibitor JTE-052 improves skin barrier function through suppressing signal transducer and activator of transcription 3 signaling. The Journal of allergy and clinical immunology 136, 667-677 e667, doi:10.1016/j.jaci.2015.03.051 (2015). [PubMed: 26115905]

95. Bao L, Shi VY \& Chan LS IL-4 regulates chemokine CCL26 in keratinocytes through the Jak1, 2/ Stat6 signal transduction pathway: Implication for atopic dermatitis. Mol Immunol 50, 91-97, doi: 10.1016/j.molimm.2011.12.008 (2012). [PubMed: 22226123]

96. Lee HY, Stieger M, Yawalkar N \& Kakeda M Cytokines and chemokines in irritant contact dermatitis. Mediators Inflamm 2013, 916497, doi:10.1155/2013/916497 (2013). [PubMed: 24371376]

97. Amano $\mathrm{W}$ et al. JAK inhibitor JTE-052 regulates contact hypersensitivity by downmodulating T cell activation and differentiation. J Dermatol Sci 84, 258-265, doi:10.1016/j.jdermsci. 2016.09.007 (2016). [PubMed: 27665390]

98. King B, Lee AI \& Choi J Treatment of Hypereosinophilic Syndrome with Cutaneous Involvement with the JAK Inhibitors Tofacitinib and Ruxolitinib. J Invest Dermatol, doi:10.1016/j.jid. 2016.10.044 (2016).

99. Bissonnette R et al. Topical tofacitinib for atopic dermatitis: a phase IIa randomized trial. Br J Dermatol 175, 902-911, doi:10.1111/bjd.14871 (2016). [PubMed: 27423107]

100. Meng J \& Steinhoff M Molecular mechanisms of pruritus. Curr Res Transl Med 64, 203-206, doi: 10.1016/j.retram.2016.08.006 (2016). [PubMed: 27939459]

101. Craiglow BG \& King BA Tofacitinib Citrate for the Treatment of Vitiligo: A PathogenesisDirected Therapy. JAMA Dermatol, doi:10.1001/jamadermatol.2015.1520 (2015). 
102. Koga T et al. Successful treatment of palmoplantar pustulosis with rheumatoid arthritis, with tofacitinib: Impact of this JAK inhibitor on T-cell differentiation. Clin Immunol 173, 147-148, doi:10.1016/j.clim.2016.10.003 (2016). [PubMed: 27720846]

103. Damsky W \& King BA Idiopathic erythema multiforme: Evidence of underlying Janus kinasesignal transducer and activator of transcription activation and successful treatment with tofacitinib. JAAD Case Rep 2, 502-504, doi:10.1016/j.jdcr.2016.10.009 (2016). [PubMed: 28004029]

104. Vincenti $F$ et al. Randomized phase $2 b$ trial of tofacitinib (CP-690,550) in de novo kidney transplant patients: efficacy, renal function and safety at 1 year. Am J Transplant 12, 2446-2456, doi:10.1111/j.1600-6143.2012.04127.x (2012). [PubMed: 22682022]

105. Vincenti $F$ et al. Evaluation of the effect of tofacitinib exposure on outcomes in kidney transplant patients. Am J Transplant 15, 1644-1653, doi:10.1111/ajt.13181 (2015). [PubMed: 25649117]

106. Moore CA et al. Janus kinase inhibition for immunosuppression in solid organ transplantation: Is there a role in complex immunologic challenges? Hum Immunol, doi:10.1016/j.humimm. 2016.12.005 (2016).

107. Montealegre G et al. Preliminary response to Janus kinase inhibition with baricitinib in chronic atypical neutrophilic dermatosis with lipodystrophy and elevated temperatures (CANDLE). Pediatric Rheumatology 13, O31, doi:10.1186/1546-0096-13-s1-o31 (2015).

108. Montealegre Sanchez GA et al. Lipodystrophy and Elevated Temperatures (CANDLE): Clinical Characterization and Initial Response To Janus Kinase Inhibition With Baricitinib. Annals of the Rheumatic Diseases 65, S758-S759 (2013).

109. Furumoto $\mathrm{Y}$ et al. Tofacitinib ameliorates murine lupus and its associated vascular dysfunction. Arthritis Rheumatol, doi:10.1002/art.39818 (2016).

110. Paik JJ \& Christopher-Stine L A case of refractory dermatomyositis responsive to tofacitinib. Semin Arthritis Rheum, doi:10.1016/j.semarthrit.2016.08.009 (2016).

111. Kurtzman DJ et al. Tofacitinib Citrate for Refractory Cutaneous Dermatomyositis: An Alternative Treatment. JAMA Dermatol 152, 944-945, doi:10.1001/jamadermatol.2016.0866 (2016). [PubMed: 27120749]

112. Hornung $\mathrm{T}$ et al. Remission of recalcitrant dermatomyositis treated with ruxolitinib. The New England journal of medicine 371, 2537-2538, doi:10.1056/NEJMc1412997 (2014).

113. Liew SH et al. Tofacitinib (CP-690,550), a Janus kinase inhibitor for dry eye disease: results from a phase 1/2 trial. Ophthalmology 119, 1328-1335, doi:10.1016/j.ophtha.2012.01.028 (2012). [PubMed: 22525048]

114. The definition and classification of dry eye disease: report of the Definition and Classification Subcommittee of the International Dry Eye WorkShop (2007). Ocul Surf 5, 75-92 (2007). [PubMed: 17508116]

115. Rothenberg ME et al. Treatment of patients with the hypereosinophilic syndrome with mepolizumab. The New England journal of medicine 358, 1215-1228, doi:10.1056/ NEJMoa070812 (2008). [PubMed: 18344568]

116. Rimar D et al. Tofacitinib for polyarteritis nodosa: a tailored therapy. Ann Rheum Dis 75, 2214 2216, doi:10.1136/annrheumdis-2016-209330 (2016). [PubMed: 27558986]

117. Okiyama N et al. Reversal of CD8 T-cell-mediated mucocutaneous graft-versus-host-like disease by the JAK inhibitor tofacitinib. J Invest Dermatol 134, 992-1000, doi:10.1038/jid.2013.476 (2014). [PubMed: 24213371]

118. Martin R, Sospedra M, Rosito M \& Engelhardt B Current multiple sclerosis treatments have improved our understanding of MS autoimmune pathogenesis. Eur J Immunol 46, 2078-2090, doi:10.1002/eji.201646485 (2016). [PubMed: 27467894]

119. Havrdova E et al. Activity of secukinumab, an anti-IL-17A antibody, on brain lesions in RRMS: results from a randomized, proof-of-concept study. J Neurol 263, 1287-1295, doi:10.1007/ s00415-016-8128-x (2016). [PubMed: 27142710]

120. Tuttle K et al. in Diabetes 2015 (2015).

121. Christ A, Bekkering S, Latz E \& Riksen NP Long-term activation of the innate immune system in atherosclerosis. Semin Immunol 28, 384-393, doi:10.1016/j.smim.2016.04.004 (2016). [PubMed: 27113267] 
122. Volpato S et al. Cardiovascular Disease, Interleukin-6, and Risk of Mortality in Older Women : The Women's Health and Aging Study. Circulation 103, 947-953, doi:10.1161/01.cir.103.7.947 (2001). [PubMed: 11181468]

123. Szelag M, Piaszyk-Borychowska A, Plens-Galaska M, Wesoly J \& Bluyssen HA Targeted inhibition of STATs and IRFs as a potential treatment strategy in cardiovascular disease. Oncotarget 7, 48788-48812, doi:10.18632/oncotarget.9195 (2016). [PubMed: 27166190]

124. Dowty ME et al. An Analysis of in-Vitro Cytokine Inhibition Profiles of Tofacitinib and Other Janus Kinase Inhibitors at Clinically-Meaningful Concentrations. Arthritis and Rheumatism 66 (2014).

125. Strand V et al. Systematic review and meta-analysis of serious infections with tofacitinib and biologic disease-modifying antirheumatic drug treatment in rheumatoid arthritis clinical trials. Arthritis Res Ther 17, 362, doi:10.1186/s13075-015-0880-2 (2015). [PubMed: 26669566]

126. Wathes R, Moule S \& Milojkovic D Progressive multifocal leukoencephalopathy associated with ruxolitinib. The New England journal of medicine 369, 197-198, doi:10.1056/NEJMc1302135 (2013).

127. Winthrop KL The emerging safety profile of JAK inhibitors in rheumatic disease. Nat Rev Rheumatol 13, 234-243, doi:10.1038/nrrheum.2017.23 (2017). [PubMed: 28250461]

128. van Vollenhoven R et al. THU0199 Tofacitinib, An Oral Janus Kinase Inhibitor, in The Treatment of Rheumatoid Arthritis: Changes in Lymphocytes and Lymphocyte Subset Counts and Reversibility after Up To 8 Years of Tofacitinib Treatment. Annals of the Rheumatic Diseases 75, 258-258, doi:10.1136/annrheumdis-2016-eular.2134 (2016).

129. Rizzi M et al. Impact of tofacitinib treatment on human B-cells in vitro and in vivo. J Autoimmun, doi:10.1016/j.jaut.2016.10.005 (2016).

130. Fink K Origin and Function of Circulating Plasmablasts during Acute Viral Infections. Front Immunol 3, 78, doi:10.3389/fimmu.2012.00078 (2012). [PubMed: 22566959]

131. Winthrop KL et al. The effect of tofacitinib on pneumococcal and influenza vaccine responses in rheumatoid arthritis. Ann Rheum Dis, doi:10.1136/annrheumdis-2014-207191 (2015).

132. Singh JA et al. 2015 American College of Rheumatology Guideline for the Treatment of Rheumatoid Arthritis. Arthritis care \& research 68, 1-25, doi:10.1002/acr.22783 (2016). [PubMed: 26545825]

133. Taylor $P$ et al. Baricitinib Versus Placebo or Adalimumab in Patients with Active Rheumatoid Arthritis (RA) and an Inadequate Response to Background Methotrexate Therapy: Results of a Phase 3 Study (abstract). Arthritis and Rheumatism 67 (2015).

134. Fleischmann R et al. Baricitinib, Methotrexate, or Combination in Patients with Rheumatoid Arthritis and No or Limited Prior Disease-Modifying Antirheumatic Drug Treatment. Arthritis Rheumatol, doi:10.1002/art.39953 (2016).

135. Solomon DH et al. Disease activity in rheumatoid arthritis and the risk of cardiovascular events. Arthritis Rheumatol 67, 1449-1455, doi:10.1002/art.39098 (2015). [PubMed: 25776112]

136. Alemao E et al. Cardiovascular risk factor management in patients with RA compared to matched non-RA patients. Rheumatology (Oxford) 55, 809-816, doi:10.1093/rheumatology/kev427 (2016). [PubMed: 26705329]

137. Radner H, Lesperance T, Accortt NA \& Solomon DH Incidence and Prevalence of Cardiovascular Risk Factors Among Patients With Rheumatoid Arthritis, Psoriasis, or Psoriatic Arthritis. Arthritis care \& research, doi:10.1002/acr.23171 (2016).

138. Mok CC et al. Prevalence of atherosclerotic risk factors and the metabolic syndrome in patients with chronic inflammatory arthritis. Arthritis care \& research 63, 195-202, doi:10.1002/acr. 20363 (2011). [PubMed: 20890981]

139. Hak AE, Karlson EW, Feskanich D, Stampfer MJ \& Costenbader KH Systemic lupus erythematosus and the risk of cardiovascular disease: results from the nurses' health study. Arthritis Rheum 61, 1396-1402, doi:10.1002/art.24537 (2009). [PubMed: 19790130]

140. Tobin AM et al. Cardiovascular disease and risk factors in patients with psoriasis and psoriatic arthritis. J Rheumatol 37, 1386-1394, doi:10.3899/jrheum.090822 (2010). [PubMed: 20472927] 
141. Denny MF et al. Interferon-alpha promotes abnormal vasculogenesis in lupus: a potential pathway for premature atherosclerosis. Blood 110, 2907-2915, doi:10.1182/blood-2007-05-089086 (2007). [PubMed: 17638846]

142. Scheller J, Garbers C \& Rose-John S Interleukin-6: from basic biology to selective blockade of pro-inflammatory activities. Semin Immunol 26, 2-12, doi:10.1016/j.smim.2013.11.002 (2014). [PubMed: 24325804]

143. Souto A et al. Lipid profile changes in patients with chronic inflammatory arthritis treated with biologic agents and tofacitinib in randomized clinical trials: a systematic review and metaanalysis. Arthritis Rheumatol 67, 117-127, doi:10.1002/art.38894 (2015). [PubMed: 25303044]

144. Rao VU et al. An evaluation of risk factors for major adverse cardiovascular events during tocilizumab therapy. Arthritis Rheumatol 67, 372-380, doi:10.1002/art.38920 (2015). [PubMed: 25332171]

145. Charles-Schoeman C et al. Potential mechanisms leading to the abnormal lipid profile in patients with rheumatoid arthritis versus healthy volunteers and reversal by tofacitinib. Arthritis Rheumatol 67, 616-625, doi:10.1002/art.38974 (2015). [PubMed: 25470338]

146. Charles-Schoeman C et al. Cardiovascular safety findings in patients with rheumatoid arthritis treated with tofacitinib, an oral Janus kinase inhibitor. Semin Arthritis Rheum 46, 261-271, doi: 10.1016/j.semarthrit.2016.05.014 (2016). [PubMed: 27443588]

147. Wu JJ et al. Effects of tofacitinib on cardiovascular risk factors and cardiovascular outcomes based on phase III and long-term extension data in patients with plaque psoriasis. J Am Acad Dermatol 75, 897-905, doi:10.1016/j.jaad.2016.06.012 (2016). [PubMed: 27498960]

148. Charles-Schoeman C et al. Effects of tofacitinib and other DMARDs on lipid profiles in rheumatoid arthritis: implications for the rheumatologist. Semin Arthritis Rheum 46, 71-80, doi: 10.1016/j.semarthrit.2016.03.004 (2016). [PubMed: 27079757]

149. Kume K Tofacitinib Improves Arterial Stiffness Despite up-Regulating Serum Cholesterol with Chronic Cardiovascular Disease in Methotrexate-Resistant Active Rheumatoid Arthritis Patients. a Cohort Study. Arthritis and Rheumatism 66, S209 (2014).

150. Xie F, Yun H, Bernatsky S \& Curtis JR Brief Report: Risk of Gastrointestinal Perforation Among Rheumatoid Arthritis Patients Receiving Tofacitinib, Tocilizumab, or Other Biologic Treatments. Arthritis Rheumatol 68, 2612-2617, doi:10.1002/art.39761 (2016). [PubMed: 27213279]

151. Dudakov JA, Hanash AM \& van den Brink MR Interleukin-22: immunobiology and pathology. Annu Rev Immunol 33, 747-785, doi:10.1146/annurev-immunol-032414-112123 (2015). [PubMed: 25706098]

152. Shouval DS et al. Interleukin 10 receptor signaling: master regulator of intestinal mucosal homeostasis in mice and humans. Adv Immunol 122, 177-210, doi:10.1016/ B978-0-12-800267-4.00005-5 (2014). [PubMed: 24507158]

153. Sivaraman P \& Cohen SB Malignancy and Janus Kinase Inhibition. Rheum Dis Clin North Am 43, 79-93, doi:10.1016/j.rdc.2016.09.008 (2017). [PubMed: 27890175]

154. Kremer JM et al. Evaluation of the effect of tofacitinib on measured glomerular filtration rate in patients with active rheumatoid arthritis: results from a randomised controlled trial. Arthritis Res Ther 17, 95, doi:10.1186/s13075-015-0612-7 (2015). [PubMed: 25889308]

155. Isaacs JD et al. Changes in serum creatinine in patients with active rheumatoid arthritis treated with tofacitinib: results from clinical trials. Arthritis Res Ther 16, R158, doi:10.1186/ar4673 (2014). [PubMed: 25063045]

156. Chapin RE et al. Effects of the Janus Kinase Inhibitor, Tofacitinib, on Testicular Leydig Cell Hyperplasia and Adenoma in Rats, and on Prolactin Signaling in Cultured Primary Rat Leydig Cells. Toxicol Sci, doi:10.1093/toxsci/kfw197 (2016).

157. Van Rompaey L et al. Preclinical characterization of GLPG0634, a selective inhibitor of JAK1, for the treatment of inflammatory diseases. J Immunol 191, 3568-3577, doi:10.4049/jimmunol. 1201348 (2013). [PubMed: 24006460]

158. Menet CJ et al. Triazolopyridines as selective JAK1 inhibitors: from hit identification to GLPG0634. J Med Chem 57, 9323-9342, doi:10.1021/jm501262q (2014). [PubMed: 25369270]

159. Kettle JG et al. Inhibitors of JAK-family kinases: an update on the patent literature 2013-2015, part 1. Expert Opin Ther Pat, 1-17, doi:10.1080/13543776.2017.1252753 (2016). 
160. Kettle JG et al. Inhibitors of JAK-family kinases: an update on the patent literature 2013-2015, part 2. Expert Opin Ther Pat 27, 145-161, doi:10.1080/13543776.2017.1252754 (2017). [PubMed: 27774822]

161. Shimozaki K, Nakajima K, Hirano T \& Nagata S Involvement of STAT3 in the Granulocyte Colony-stimulating Factor-induced Differentiation of Myeloid Cells. Journal of Biological Chemistry 272, 25184-25189, doi:10.1074/jbc.272.40.25184 (1997). [PubMed: 9312131]

162. Vermeire $S$ et al. Clinical remission in patients with moderate-to-severe Crohn's disease treated with filgotinib (the FITZROY study): results from a phase 2, double-blind, randomised, placebocontrolled trial. The Lancet, doi:10.1016/s0140-6736(16)32537-5 (2016).

163. Voss J et al. THU0127 Pharmacodynamics of A Novel JAK1 Selective Inhibitor in Rat Arthritis and Anemia Models and in Healthy Human Subjects. Annals of the Rheumatic Diseases 73, 222.222-222, doi:10.1136/annrheumdis-2014-eular.3823 (2014).

164. Graff C et al. in American College of Rheumatology Annual Meeting (2014).

165. Mohamed ME, Jungerwirth S, Asatryan A, Jiang P \& Othman A Assessment of the Effect of CYP3A Inhibition, CYP Induction, OATP1B Inhibition and Administration of High-Fat Meal on the Pharmacokinetics of the Potent and Selective JAK1 Inhibitor ABT-494 [abstract]. Arthritis and Rheumatism 67 (suppl 10) (2015).

166. Kremer JM et al. A Phase IIb Study of ABT-494, a Selective JAK-1 Inhibitor, in Patients With Rheumatoid Arthritis and an Inadequate Response to Anti-Tumor Necrosis Factor Therapy. Arthritis Rheumatol 68, 2867-2877, doi:10.1002/art.39801 (2016). [PubMed: 27389975]

167. Genovese MC et al. Efficacy and Safety of ABT-494, a Selective JAK-1 Inhibitor, in a Phase IIb Study in Patients With Rheumatoid Arthritis and an Inadequate Response to Methotrexate. Arthritis Rheumatol 68, 2857-2866, doi:10.1002/art.39808 (2016). [PubMed: 27390150]

168. Henriques C in Rheumatoid Arthritis News (2016).

169. Ludbrook VJ et al. Investigation of selective JAK1 inhibitor GSK2586184 for the treatment of psoriasis in a randomized placebo-controlled phase IIa study. Br J Dermatol 174, 985-995, doi: 10.1111/bjd.14399 (2016). [PubMed: 26785220]

170. Kahl L et al. Safety, tolerability, efficacy and pharmacodynamics of the selective JAK1 inhibitor GSK2586184 in patients with systemic lupus erythematosus. Lupus 25, 1420-1430, doi: 10.1177/0961203316640910 (2016). [PubMed: 27055521]

171. Clark JD, Flanagan ME \& Telliez JB Discovery and development of Janus kinase (JAK) inhibitors for inflammatory diseases. J Med Chem 57, 5023-5038, doi:10.1021/jm401490p (2014). [PubMed: 24417533]

172. Genovese MC, van Vollenhoven RF, Pacheco-Tena C, Zhang Y \& Kinnman N VX-509 (Decernotinib), an Oral Selective Janus Kinase 3 Inhibitor, in Combination With Methotrexate in Patients With Rheumatoid Arthritis. Arthritis Rheumatol, doi:10.1002/art.39473 (2015).

173. Genovese MC, Yang F, Ostergaard M \& Kinnman N Efficacy of VX-509 (decernotinib) in combination with a disease-modifying antirheumatic drug in patients with rheumatoid arthritis: clinical and MRI findings. Ann Rheum Dis 75, 1979-1983, doi:10.1136/ annrheumdis-2015-208901 (2016). [PubMed: 27084959]

174. Farmer LJ et al. Discovery of VX-509 (Decernotinib): A Potent and Selective Janus Kinase 3 Inhibitor for the Treatment of Autoimmune Diseases. J Med Chem 58, 7195-7216, doi:10.1021/ acs.jmedchem.5b00301 (2015). [PubMed: 26230873]

175. Fleischmann RM et al. A randomized, double-blind, placebo-controlled, twelve-week, doseranging study of decernotinib, an oral selective JAK-3 inhibitor, as monotherapy in patients with active rheumatoid arthritis. Arthritis Rheumatol 67, 334-343, doi:10.1002/art.38949 (2015). [PubMed: 25385260]

176. Huang J, Yang F, Yogaratnam J \& Shen J SAT0227 The Effect of Deuteration of VX-509 (Decernotinib) on Drug-Drug Interactions (DDI) with Midazolam. Annals of the Rheumatic Diseases 74, 740.742-740, doi:10.1136/annrheumdis-2015-eular.1810 (2015).

177. Goedken ER et al. Tricyclic covalent inhibitors selectively target Jak3 through an active site thiol. J Biol Chem 290, 4573-4589, doi:10.1074/jbc.M114.595181 (2015). [PubMed: 25552479] 
178. Telliez JB et al. Discovery of a JAK3-Selective Inhibitor: Functional Differentiation of JAK3Selective Inhibition over pan-JAK or JAK1-Selective Inhibition. ACS Chem Biol 11, 3442-3451, doi:10.1021/acschembio.6b00677 (2016). [PubMed: 27791347]

179. Miao W,C,M, Greenwood J, Kapeller R \& Westlin W Potent and Selective Tyk2 Inhibitor Highly Efficacious in Rodent Models of Inflammatory Bowel Disease and Psoriasis [abstract]. Arthritis Rheum 68 (2016).

180. Masse $\mathrm{C}$ et al. Identification of highly potent and selective Tyk2 inhibitors for the treatment of autoimmune diseases through structure-based drug design (THER2P.961). The Journal of Immunology 194, 67 (2015).

181. Gillooly K et al. BMS-986165 Is a Highly Potent and Selective Allosteric Inhibitor of Tyk2, Blocks IL-12, IL-23 and Type I Interferon Signaling and Provides for Robust Efficacy in Preclinical Models of Systemic Lupus Erythematosus and Inflammatory Bowel Disease [abstract]. Arthritis Rheum 68 (2016).

182. Moslin R et al. in 25th Enzyme Mechanisms Conference (St. Pete Beach, Florida, 2017).

183. Fensome A et al. in American Chemical Society 2016 Annual Meeting and Expo (Philadelphia, 2016).

184. Works MG et al. Inhibition of TYK2 and JAK1 ameliorates imiquimod-induced psoriasis-like dermatitis by inhibiting IL-22 and the IL-23/IL-17 axis. J Immunol 193, 3278-3287, doi: 10.4049/jimmunol.1400205 (2014). [PubMed: 25156366]

185. Mocsai A, Ruland J \& Tybulewicz VL The SYK tyrosine kinase: a crucial player in diverse biological functions. Nature reviews. Immunology 10, 387-402, doi:10.1038/nri2765 (2010).

186. Weinblatt ME et al. An oral spleen tyrosine kinase (Syk) inhibitor for rheumatoid arthritis. The New England journal of medicine 363, 1303-1312, doi:10.1056/NEJMoa1000500 (2010). [PubMed: 20879879]

187. Coffey $\mathrm{G}$ et al. The novel kinase inhibitor PRT062070 (Cerdulatinib) demonstrates efficacy in models of autoimmunity and B-cell cancer. J Pharmacol Exp Ther 351, 538-548, doi:10.1124/ jpet.114.218164 (2014). [PubMed: 25253883]

188. Hume DA \& MacDonald KP Therapeutic applications of macrophage colony-stimulating factor-1 (CSF-1) and antagonists of CSF-1 receptor (CSF-1R) signaling. Blood 119, 1810-1820, doi: 10.1182/blood-2011-09-379214 (2012). [PubMed: 22186992]

189. Kindler T, Lipka DB \& Fischer T FLT3 as a therapeutic target in AML: still challenging after all these years. Blood 116, 5089-5102, doi:10.1182/blood-2010-04-261867 (2010). [PubMed: 20705759]

190. Madan B et al. SB1578, a novel inhibitor of JAK2, FLT3, and c-Fms for the treatment of rheumatoid arthritis. J Immunol 189, 4123-4134, doi:10.4049/jimmunol.1200675 (2012). [PubMed: 22962687]

191. William AD et al. Discovery of the macrocycle (9E)-15-(2-(pyrrolidin-1-yl)ethoxy)-7,12,25trioxa-19,21,24-triaza-tetracyclo[18. 3.1.1(2,5).1(14,18)] hexacosa-1(24),2,4,9,14(26), 15,17,20,22-nonaene (SB1578), a potent inhibitor of janus kinase 2/fms-like tyrosine kinase-3 (JAK2/FLT3) for the treatment of rheumatoid arthritis. J Med Chem 55, 2623-2640, doi:10.1021/ jm201454n (2012). [PubMed: 22339472]

192. Smith GA, Uchida K, Weiss A \& Taunton J Essential biphasic role for JAK3 catalytic activity in IL-2 receptor signaling. Nat Chem Biol 12, 373-379, doi:10.1038/nchembio.2056 (2016). [PubMed: 27018889]

193. Haan C et al. Jak1 has a dominant role over Jak3 in signal transduction through gammaccontaining cytokine receptors. Chem Biol 18, 314-323, doi:10.1016/j.chembiol.2011.01.012 (2011). [PubMed: 21439476]

194. Karaman MW et al. A quantitative analysis of kinase inhibitor selectivity. Nat Biotechnol 26, 127-132, doi:10.1038/nbt1358 (2008). [PubMed: 18183025]

195. Li L et al. Beryllium-induced lung disease exhibits expression profiles similar to sarcoidosis. Eur Respir J 47, 1797-1808, doi:10.1183/13993003.01469-2015 (2016). [PubMed: 27103383]

196. Moodley D et al. Network pharmacology of JAK inhibitors. Proc Natl Acad Sci U S A 113, 9852-9857, doi:10.1073/pnas.1610253113 (2016). [PubMed: 27516546] 
197. Barroso N \& Furst DE A Case Series on Patients on Tofacitinib in Combination with a Biologic [abstract]. Arthritis and Rheumatology 68 (2016).

198. Vahedi G et al. Super-enhancers delineate disease-associated regulatory nodes in T cells. Nature 520, 558-562, doi:10.1038/nature14154 (2015). [PubMed: 25686607]

199. McNally R \& Eck MJ JAK-cytokine receptor recognition, unboxed. Nature structural \& molecular biology 21, 431-433, doi:10.1038/nsmb.2824 (2014).

200. Chen X et al. Crystal Structure of a Tyrosine Phosphorylated STAT-1 Dimer Bound to DNA. Cell 93, 827-839, doi:10.1016/s0092-8674(00)81443-9 (1998). [PubMed: 9630226]

201. Kremer $\mathbf{J}$ et al. Tofacitinib in combination with nonbiologic disease-modifying antirheumatic drugs in patients with active rheumatoid arthritis: a randomized trial. Ann Intern Med 159, $253-$ 261, doi:10.7326/0003-4819-159-4-201308200-00006 (2013). [PubMed: 24026258]

202. Gladman DD et al. in American College or Rheumatology Annual Meeting (Washington, D. C., 2016).

203. Papp KA et al. Tofacitinib, an oral Janus kinase inhibitor, for the treatment of chronic plaque psoriasis: results from two randomized, placebo-controlled, phase III trials. Br J Dermatol 173, 949-961, doi:10.1111/bjd.14018 (2015). [PubMed: 26149717]

204. Sandborn WJ et al. (European Crohn's and Colitis Organization, 2016). 

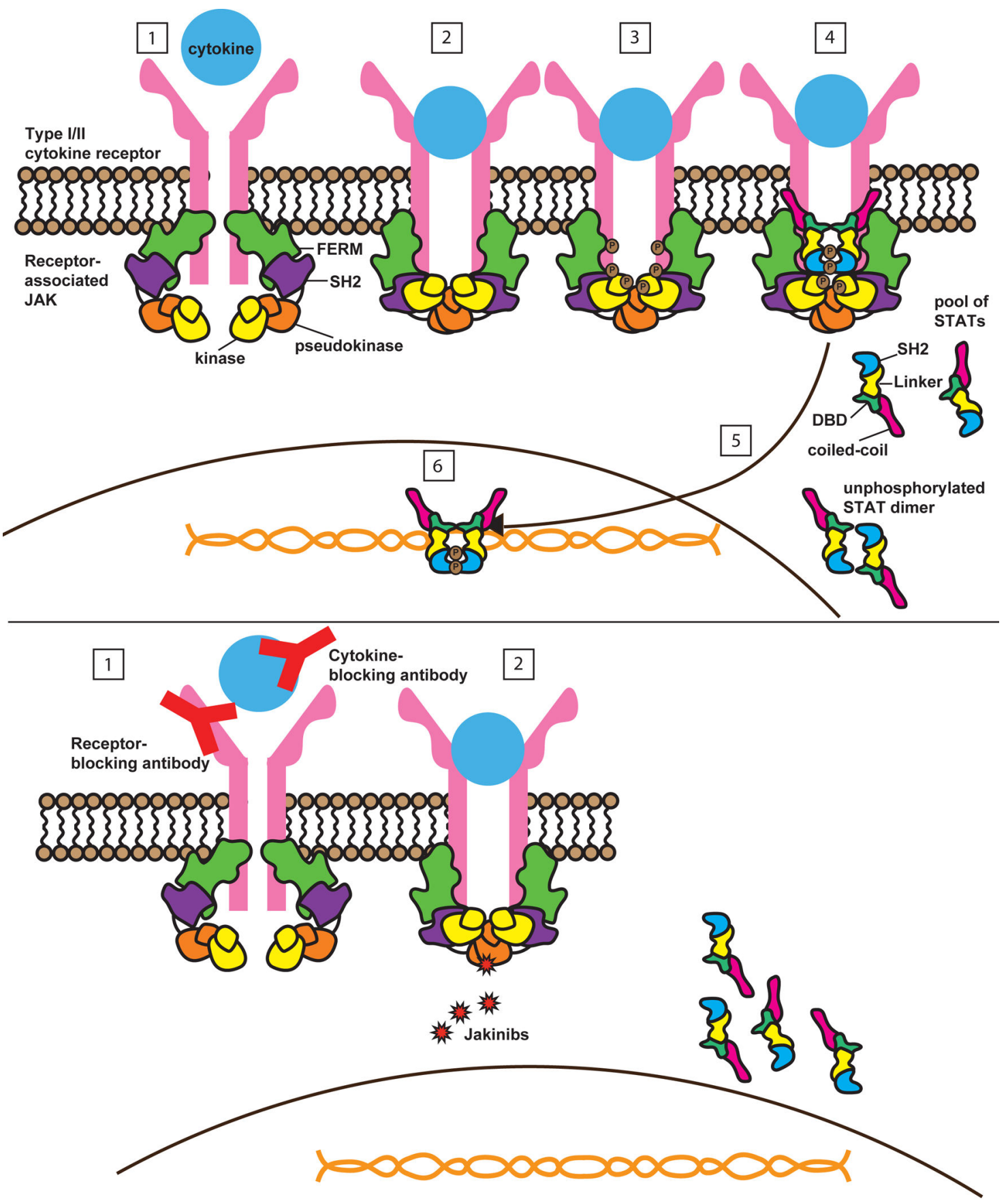

Figure 1: Signalling by type I and II cytokine receptors.

(A) Type I and II cytokine receptors comprise subunits that physically associate with Janus kinases (JAKs). Type I/II cytokine receptors do not have any enzymatic activity but instead depend upon JAKs to transduce intracellular signals. JAK proteins share 4 components: the kinase domain, the pseudokinase domain, the FERM (Four-point-one protein, Ezrin, Radixin, Moesin) domain, and the SH2-like domain. The canonical JAK/STAT pathway is initiated by extracellular association of cytokines with their cognate receptors (1). This activates the receptor, resulting in apposition of receptor-associated JAKs (2). JAKs are 
tyrosine kinases, so upon activation they transfer phosphate from ATP to tyrosine residues on other proteins, including cytokine receptors and JAKs themselves. This is an important event, as tyrosine phosphorylation of kinases, including JAKs, triggers their enzymatic activity. Tyrosine phosphorylation of receptors (3) creates docking sites for signaling molecules including signal transducers and activators of transcription (STATs), which also undergo JAK-mediated phosphorylation of their tyrosine residues (4), leading to STAT dimerization, nuclear translocation (5), DNA binding and target gene induction (6). (B). Monoclonal antibodies can block Type I/II cytokines and their receptors. In contrast, jakinibs block cytokine signaling by inhibiting kinase activity. This prevents JAKs from phosphorylating STATs and other substrates, so that intracellular signals cannot be transduced. Because JAKs are critical for multiple different cytokines, jakinibs block the action of a range of cytokines, unlike biologics. First generation jakinibs block multiple JAKs whereas second generation jakinibs may have more selectivity for JAKs and so may inhibit a narrow range of cytokines. Cytokine receptors, JAK and STATs are drawn based on structural information 199,200. 


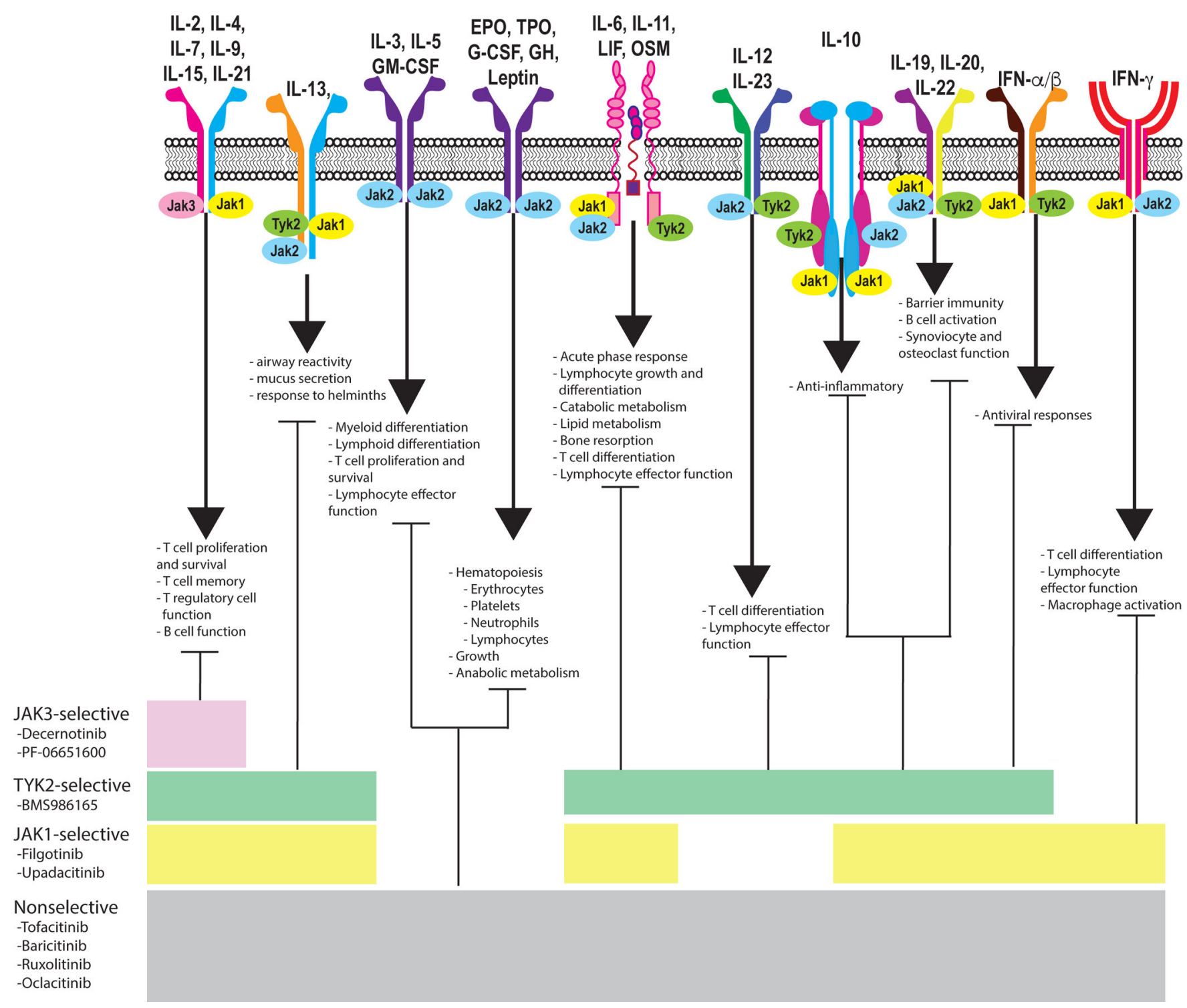

Figure 2: Effects of targeting different JAKs.

Type I and II cytokine receptors physically associate with JAKs, which transduce downstream intracellular signals. Different receptors associate with different JAKs, so that selective blockade of one JAK can inhibit a specific biologic function while allowing other JAK-dependent cytokines to signal normally. For example, selective blockade of JAK3, which is associated exclusively with the common gamma chain receptor, should inhibit $\mathrm{T}$ cell, NK cell, and B cell function while leaving hematopoietic and metabolic pathways unaffected. IL, interleukin; IFN, interferon; Jak, Janus kinase; NK, natural killer 


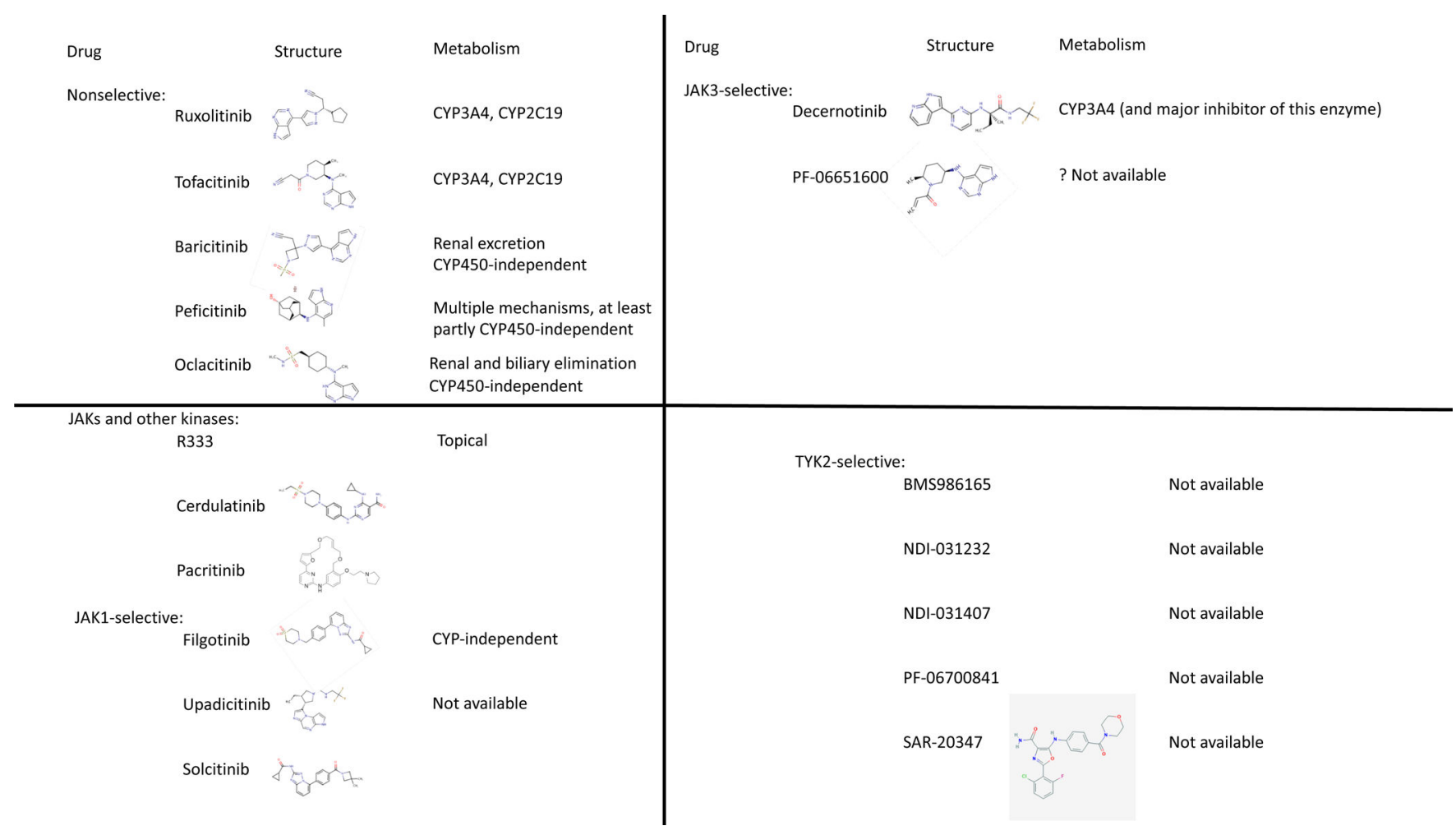

Figure 3: Chemical structure and attributes of various jakinibs

The first-generation JAK inhibitors ruxolitinib, tofacitinib, and baricitinib block multiple

JAKs. The newer pan-jakinib peficitinib has $\mathrm{IC}_{50}$ of 3.9, 5.0, 0.71 and $4.8 \mathrm{nmol} / \mathrm{L}$ for JAK1, JAK2, JAK3 and TYK2 enzymatic activity respectively. A variety of next-gen JAK inhibitors are emerging. Several block JAKs and other kinases (R333, cerdulatinib, SB-1578), while many are selective for one particular JAK isoform. Filgotinib, Upadacitinib, and Solcitinib block JAK1; Decernotinib and PF-06651600 block JAK3; and BMS986165, NDI-021232, NDI=031407, PF-06700841, and SAR-20347 all block TYK2. Chemical structures and data regarding metabolism/clearance are shown where available. $\left(\mathrm{IC}_{50}\right.$, inhibitory concentration 50\%; CYP, cytochrome P; JAK, Janus kinase) 


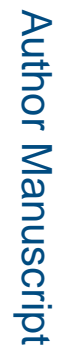

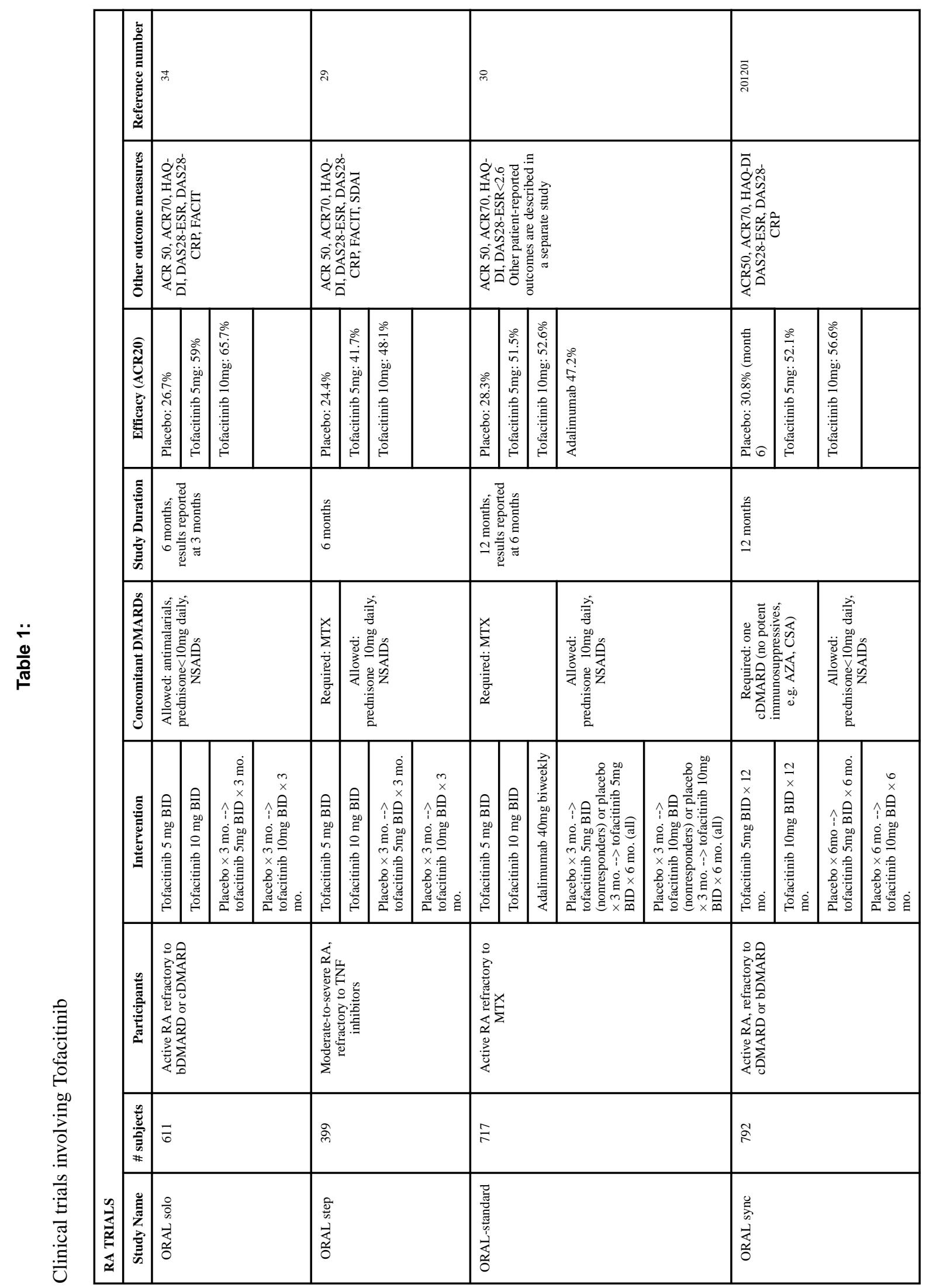

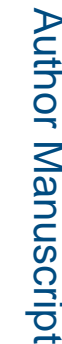

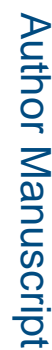




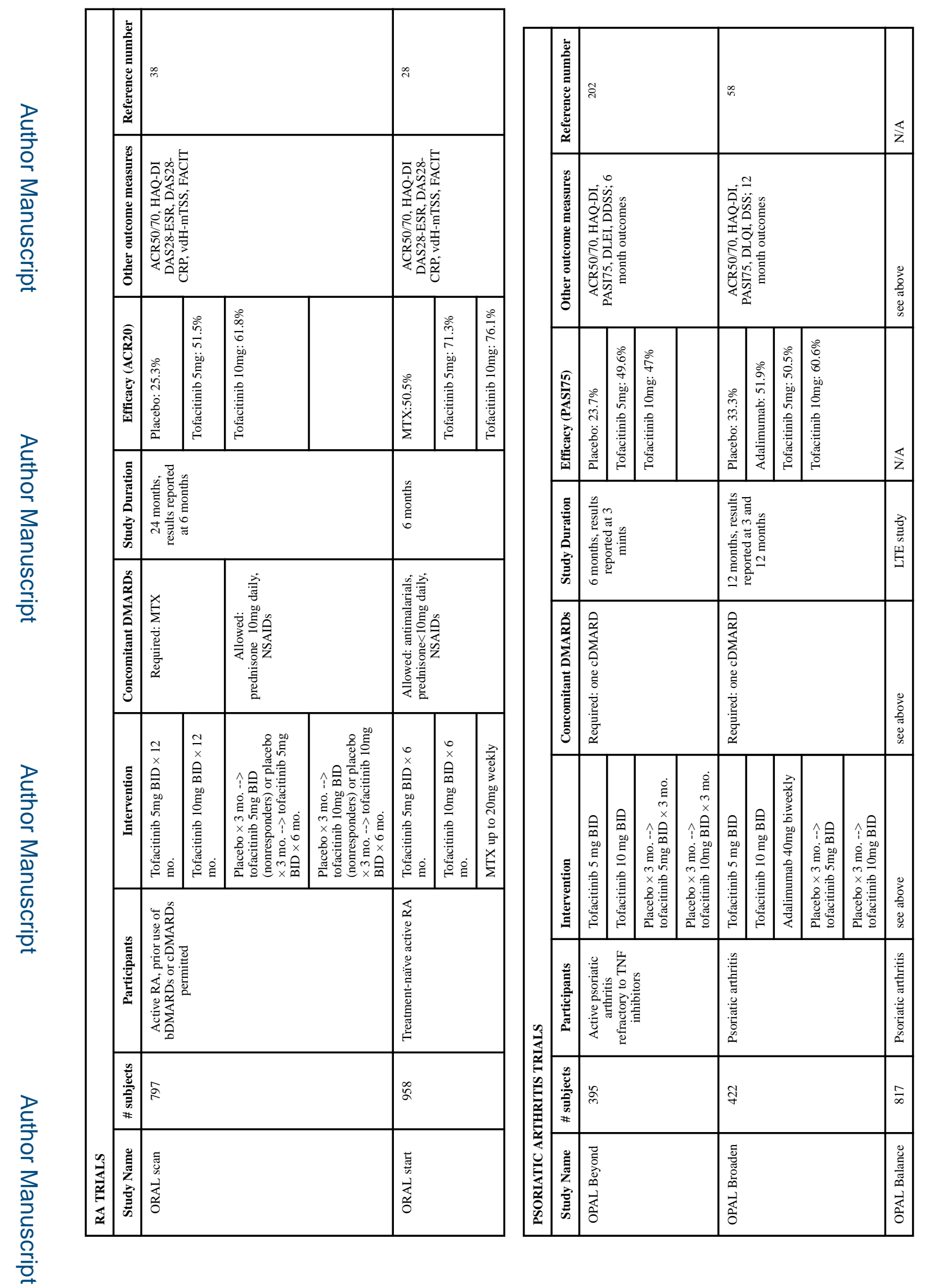

Nat Rev Drug Discov. Author manuscript; available in PMC 2018 October 02. 


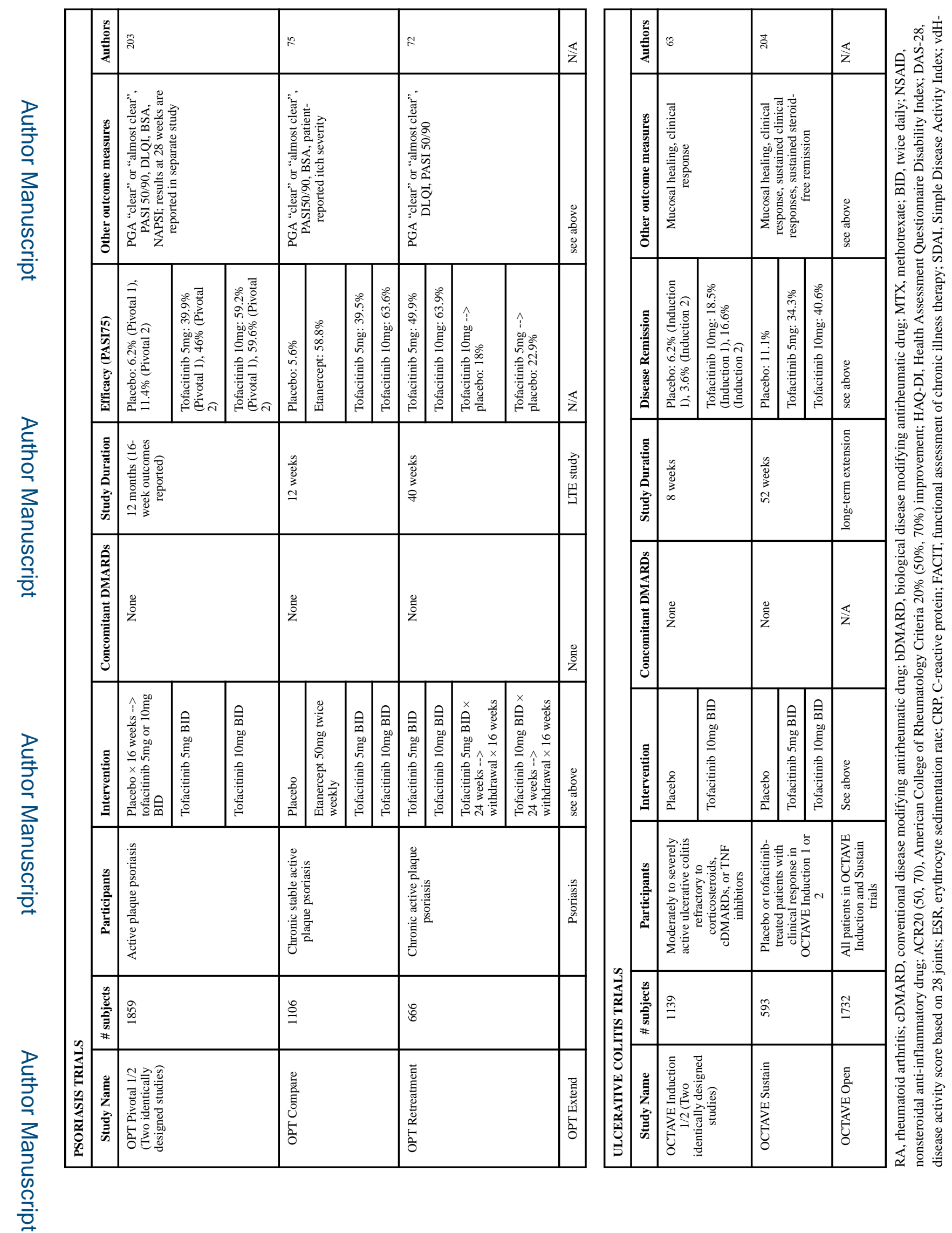

Nat Rev Drug Discov. Author manuscript; available in PMC 2018 October 02. 


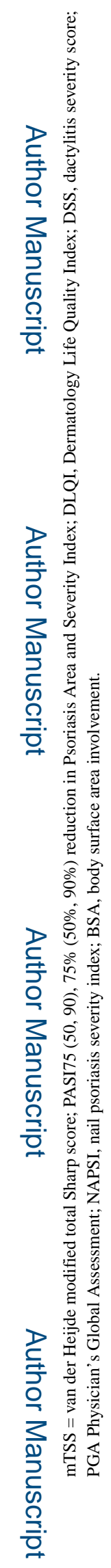




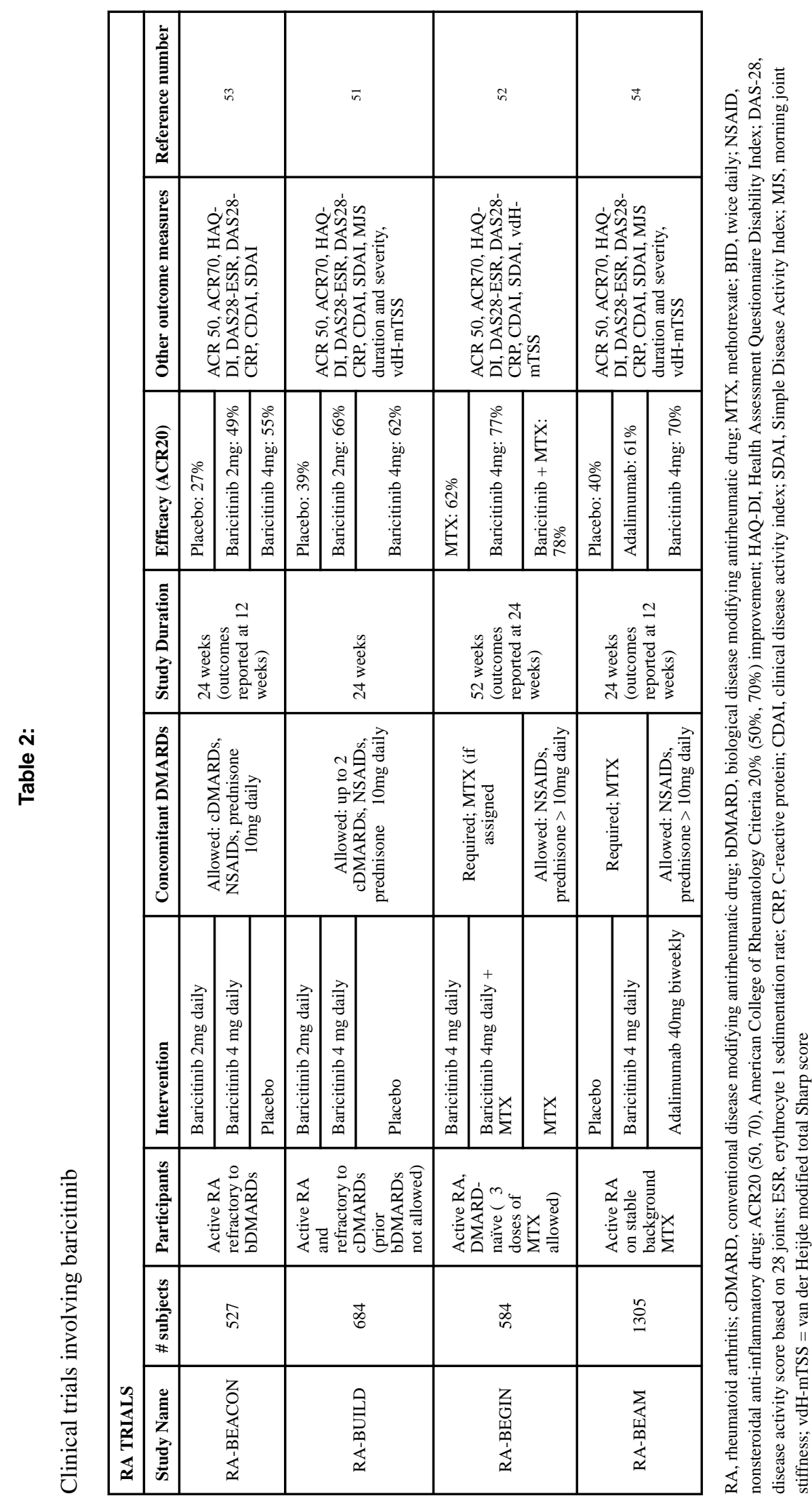

Nat Rev Drug Discov. Author manuscript; available in PMC 2018 October 02. 
Table 3:

Jakinibs that are FDA-approved or in late phase (> Phase 2) clinical trials

\begin{tabular}{|c|c|c|c|c|}
\hline Drug & Target & Status & Diseases & Clinical Trial Identifier \\
\hline \multirow{6}{*}{ Ruxolitinib (INC424) } & \multirow{6}{*}{ JAK1, JAK2 } & $\begin{array}{l}\text { FDA and EMA } \\
\quad \text { approved }\end{array}$ & Myeloproliferative neoplasms & N/A \\
\hline & & Phase II, III & Various cancers & $\begin{array}{l}\text { NCT02117479, NCT00638378, } \\
\text { NCT01562873, NCT00639002, } \\
\text { NCT02723994, NCT02119676, } \\
\text { NCT02876302, NCT01712659, others }\end{array}$ \\
\hline & & Phase II, III & GVHD & NCT02913261, NCT02953678, NCT02396628 \\
\hline & & Phase II & RA & NCT00550043 \\
\hline & & Phase II & AA & NCT01950780 \\
\hline & & Phase II & $\begin{array}{l}\text { vitiligo, AA, psoriasis, } \mathrm{AD} \\
\text { (topical) }\end{array}$ & $\begin{array}{l}\text { NCT02809976, NCT00617994, } \\
\text { NCT02553330, NCT03011892 }\end{array}$ \\
\hline \multirow{4}{*}{ Tofacitinib (CP690550) } & \multirow{4}{*}{ JAK3 $>$ JAK1 $>>(J A K 2)$} & $\begin{array}{l}\text { FDA approved, } \\
\text { EMA approval } \\
\text { recommended }\end{array}$ & RA & N/A \\
\hline & & Phase III & $\begin{array}{l}\text { Psoriasis/psoriatic arthritis, } \\
\text { UC, JIA }\end{array}$ & $\begin{array}{c}\text { NCT02592434, NCT01500551, } \\
\text { NCT01976364, NCT03000439, } \\
\text { NCT01470612, NCT01882439, NCT01877668 }\end{array}$ \\
\hline & & Phase II & $\begin{array}{l}\text { AA, Crohn's disease, AS, } \\
\text { kidney transplant }\end{array}$ & $\begin{array}{c}\text { NCT01786668, NCT01393899, } \\
\text { NCT01393626, NCT01470599, } \\
\text { NCT00615199, NCT02299297, } \\
\text { NCT02197455, NCT02312882, } \\
\text { NCT01375127, NCT00106639, } \\
\text { NCT00263328, NCT00483756, NCT00658359 }\end{array}$ \\
\hline & & Phase II & Psoriasis, AA, AD (topical) & $\begin{array}{l}\text { NCT02001181, NCT02812342, } \\
\text { NCT02193815, NCT00678561, } \\
\text { NCT01831466, NCT01246583 }\end{array}$ \\
\hline Oclacitinib & JAK1 & FDA approved & Canine allergic dermatitis & N/A \\
\hline \multirow[b]{2}{*}{ Baricitinib (INCB28050, LY3009104) } & \multirow[b]{2}{*}{ JAK1, JAK2 } & EMA approved & RA & N/A \\
\hline & & Phase II & $\begin{array}{l}\text { GVHD, giant cell arteritis, } \\
\text { diabetic nephropathy }\end{array}$ & NCT02759731, NCT03026504, NCT01683409 \\
\hline Decernotinib (VX509) & JAK3 & Phase II, III & RA & NCT01830985, NCT01590459, NCT01052194 \\
\hline \multirow{3}{*}{ Upadacitinib (ABT494) } & \multirow{3}{*}{ JAK1 } & Phase III & RA & $\begin{array}{l}\text { NCT02955212, NCT02706847, } \\
\text { NCT02720523, NCT02629159, } \\
\text { NCT02706873, NCT02675426, } \\
\text { NCT02706951, NCT02049138 }\end{array}$ \\
\hline & & Phase II, III & UC, Crohn's disease & $\begin{array}{l}\text { NCT03006068, NCT02782663, } \\
\text { NCT02819635, NCT02365649 }\end{array}$ \\
\hline & & Phase II & $\mathrm{AD}$ & NCT02925117 \\
\hline \multirow[b]{2}{*}{ Filgotinib (GLPG0634) } & \multirow[b]{2}{*}{ JAK1 } & Phase III & RA & $\begin{array}{c}\text { NCT02873936, NCT03025308, } \\
\text { NCT02886728, NCT02889796, NCT02885181 }\end{array}$ \\
\hline & & Phase II, III & UC, Crohn's disease & $\begin{array}{c}\text { NCT02048618, NCT02914600, } \\
\text { NCT02914535, NCT03077412, } \\
\text { NCT03046056, NCT02914561, NCT02914522 }\end{array}$ \\
\hline Itacitinib (INCB039110) & JAK1, JAK2 & Phase II & Psoriasis, RA, pruritis & NCT01634087, NCT01626573, NCT02909569 \\
\hline Peficitnib (ASP015K) & pan-JAK & Phase III & RA & NCT01638013 \\
\hline $\mathrm{R} 333^{*}$ & JAK, SYK & Phase II & DLE & NCT01597050 \\
\hline PF-06651600 & JAK3 & Phase II & $\mathrm{RA}, \mathrm{AA}, \mathrm{UC}$ & NCT02969044, NCT02974868, NCT02958865 \\
\hline PF-06700841 & JAK1, TYK2 & Phase II & AA, UC, psoriasis & NCT02969018, NCT02974868, NCT02958865 \\
\hline
\end{tabular}




\begin{tabular}{|c|c|c|c|c|}
\hline Drug & Target & Status & Diseases & Clinical Trial Identifier \\
\hline BMS-986165 & TYK2 & Phase II & Psoriasis & NCT02534636, NCT02931838 \\
\hline Solcitinib (GSK2586184, GLG0778) & JAK1 & Phase II & Psoriasis, SLE & $\begin{array}{r}\text { NCT02000453, NCT01782664, } \\
\text { NCT01687309, NCT01777256, NCT01953835 }\end{array}$ \\
\hline PF-04965842* & JAK1 & Phase II & Psoriasis, AD & NCT02201524, NCT02780167 \\
\hline
\end{tabular}

JAK, Janus kinase; TYK, tyrosine kinase; RA, rheumatoid arthritis; GVHD, graft-versus-host disease; SLE, systemic lupus erythematosus, FDA, Food and Drug administration; UC, ulcerative colitis

Further development has been discontinued 
Table 4:

Jakinibs under early investigation (discontinued compounds are excluded)

\begin{tabular}{|c|c|c|c|c|}
\hline Drug & Target & Status & Diseases & Clinical Trial Identifier \\
\hline SAR-20347 & Jak1/Tyk2 & preclinical & psoriasis & N/A \\
\hline Cerdulatinib (PRT-062070) & Jak/Syk & preclinical & collagen-induced arthritis & N/A \\
\hline NDI-031407 & Tyk2 & preclinical & IBD, psoriasis & N/A \\
\hline NDI-031232 & Tyk2 & preclinical & Response to IL-12 & RA \\
\hline SHR-0302 & pan-jakinib & Phase 1 & NCT02892370, NCT02665910 \\
\hline VR588 & pan-jakinib & Early phase 1 & Severe asthma & NCT02740049 \\
\hline SB-1578 & Jak2, Flt3, c-Fms & Phase 1 & Healthy subjects & NCT01235871 \\
\hline JTE-052 & nonselective & Phase 1 & Atopic dermatitis & JapicCTI-152887, JapicCTI-142494 \\
\hline
\end{tabular}

JAK, Janus kinase; TYK, tyrosine kinase; RA, rheumatoid arthritis 
Table 5:

Lesson learned from jakinibs

\begin{tabular}{|l|c|c|c|}
\hline Concept & Predicted & Not Predicted & Unknown \\
\hline Target broad spectrum of cytokines & $\mathrm{X}$ & & \\
\hline $\begin{array}{l}\text { Efficacious for autoimmune adaptive immunity-mediated disease Useful for autoinflammatory } \\
\text { innate-mediated disease }\end{array}$ & $\mathrm{X}$ & $\mathrm{X}$ & \\
\hline Efficacious for autoinflammatory innate-mediated disease & & $\mathrm{X}$ & \\
\hline Selectivity achievable & & & $\mathrm{X}$ \\
\hline Selectivity unnecessary & & $\mathrm{X}$ & \\
\hline Selectivity advantageous & & & $\mathrm{X}$ \\
\hline Pan jakinib viable & & $\mathrm{X} X$ & \\
\hline JAK1 inhibitor viable & & & $\mathrm{X}$ \\
\hline JAK2 inhibitor viable & & $\mathrm{X}$ & \\
\hline adverse effects-infection & $\mathrm{X}$ & & \\
\hline adverse effects-anemia, cytopenia & $\mathrm{X}$ & & \\
\hline Adverse effects Hyperlipidemia & & & $\mathrm{X}$ \\
\hline
\end{tabular}

JAK, Janus kinase 